\title{
Response-based methods to measure road surface irregularity: a state-of-the-art review
}

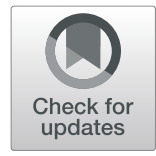

Teron Nguyen ${ }^{1,2,3,4^{*}}$ (D), Bernhard Lechner ${ }^{1}$ (D) and Yiik Diew Wong ${ }^{2,3}$ (D)

\begin{abstract}
Purpose: With the development of smart technologies, Internet of Things and inexpensive onboard sensors, many response-based methods to evaluate road surface conditions have emerged in the recent decade. Various techniques and systems have been developed to measure road profiles and detect road anomalies for multiple purposes such as expedient maintenance of pavements and adaptive control of vehicle dynamics to improve ride comfort and ride handling. A holistic review of studies into modern response-based techniques for road pavement applications is found to be lacking. Herein, the focus of this article is threefold: to provide an overview of the stateof-the-art response-based methods, to highlight key differences between methods and thereby to propose key focus areas for future research.

Methods: Available articles regarding response-based methods to measure road surface condition were collected mainly from "Scopus" database and partially from "Google Scholar". The search period is limited to the recent 15 years. Among the 130 reviewed documents, 37\% are for road profile reconstruction, 39\% for pothole detection and the remaining $24 \%$ for roughness index estimation.

Results: The results show that machine-learning techniques/data-driven methods have been used intensively with promising results but the disadvantages on data dependence have limited its application in some instances as compared to analytical/data processing methods. Recent algorithms to reconstruct/estimate road profiles are based mainly on passive suspension and quarter-vehicle-model, utilise fewer key parameters, being independent on speed variation and less computation for real-time/online applications. On the other hand, algorithms for pothole detection and road roughness index estimation are increasingly focusing on GPS accuracy, data aggregation and crowdsourcing platform for large-scale application. However, a novel and comprehensive system that is comparable to existing International Roughness Index and conventional Pavement Management System is still lacking.
\end{abstract}

Keywords: Road profile, Pothole detection, Road roughness, Accelerometer, Estimation, Classification

\section{Introduction}

A rough road gives poor ride quality, increases vehicle fuel consumption and affects vehicle handling. According to a report in Britain, potholes caused more than $£ 1$ million damages to vehicles every day in 2010 [1]. Road roughness measurement is vital for transport authorities in the quest to maintain adequate ride quality for vehicles. Knowledge of road profiles also provides information for adjusting control parameters to improve ride

\footnotetext{
* Correspondence: teron.nguyen@tum.de; teron.nguyen@tum-create.edu.sg ${ }^{1}$ Institute of Road, Railway and Airfield Construction, Technische Universität München, Baumbachstraße 7, 81245 Munich, Germany

${ }^{2}$ TUMCREATE Ltd, 1 Create Way, \#10-02 CREATE Tower, Singapore 138602,

Singapore

Full list of author information is available at the end of the article
}

comfort and ride handling, given the development of suspension system from passive to semi-active and active control in the automotive technology.

Generally speaking, road estimation algorithms [2] can be divided into three distinct types, namely contact measurement, non-contact measurement, and system response-based estimation. Conventional contact and non-contact measurements have been used worldwide as major pavement profiling methods. The primary contact measurement includes two categories: manual profilograph such as rods and levels, straight edges, walking profilers, and trailer-towed devices such as the Longitudinal Profile Analyser (LPA). Non-contact measurement includes inertial profilers such as the GM profilometer developed by General Motors (GM), and the Automated 
Pavement Profiler (APP). The advantages and disadvantages of these contact and non-contact measurements are discussed in [3-6]. In recent years, road surface monitoring instruments have transcended from dedicated vehicles with special sensors to dedicated sensors mounted on public transport vehicles, and generalpurpose sensors on privately-owned vehicles, and most recently, smartphone-enabled automated monitoring of road infrastructure [7]. This development is driven by response-based methods to indirectly assess road roughness condition using measurements of displacements, velocities, and accelerations of vehicle components, resulting in cost reduction for labour and equipment as compared with direct contact/non-contact profiling [8]. This has led to the emergence of Probe Data Performance Management (PDPM) or Vehicle Probe-based Pavement Management (PBPM) for assessing pavement quality through probe data [9]. There are three system structures by way of connected vehicle approach, fleet vehicle approach and smartphone approach. Basically, road excitation can be estimated using onboard sensors (accelerometers, gyroscopes) for individual or a combination of three key functions as follows (see Fig. 1):

1) Road Profile Reconstruction/estimation or road roughness classification - PR (e.g. Power Spectral Density - PSD), in which fast computation (e.g. in second) adapts vehicle parameters to road roughness levels;

2) Potholes Detection - PD, which detects potholes, manholes, road defects where the precise localisation is of importance; and

3) Roughness Index Estimation - RE (e.g. International roughness index - IRI or new index) for pavement maintenance where roughness data is often aggregated for a certain segment length.
A brief overview of approaches using dedicated sensors and smartphone sensors can be found in $[10,11]$, yet a comprehensive review is lacking. Herein, in this literature review paper, around 130 articles have been reviewed focusing on the methodologies but not on theories, empirical insights or conceptual model [12]. The objectives and contribution of this review are threefold. Firstly, an examination of the state-of-the-art response-based methods is conducted to provide an overview of their developments within the last 10 years. This provides a comprehensive understanding of the diversity of on-going and dominant methodologies being used. Secondly, the key pros and cons of different methods, e.g. signal processing, data-driven, threshold-based, transfer function, are highlighted. Lastly, key focus areas on the estimation of road surface irregularity are proposed as opportunities for further studies such as the inclusion of air-suspension system, improvement of current machine learning algorithms or further development of the fleet vehicle approach. The results of this review serve to shed light and provide orientation for the research community on system response-based estimation.

Figure 2 illustrates a topology of approaches to measure road surface irregularity focusing on system response-based methods with detailed applications for vehicle dynamics control (VDC) in dealing with PR for adjusting vehicle parameters to improve ride comfort and ride handling; and PBPM utilising portable onboard sensors and smartphones for PD and RE in citywide network.

The methodology for gathering "response-based methods literature database" is presented in the next section. PR algorithms for VDC are then described, followed by PD and RE algorithms for PBPM. The discussion, conclusion and outlook section reports the main results of this review study and proposes research and development gaps deserving of further study.

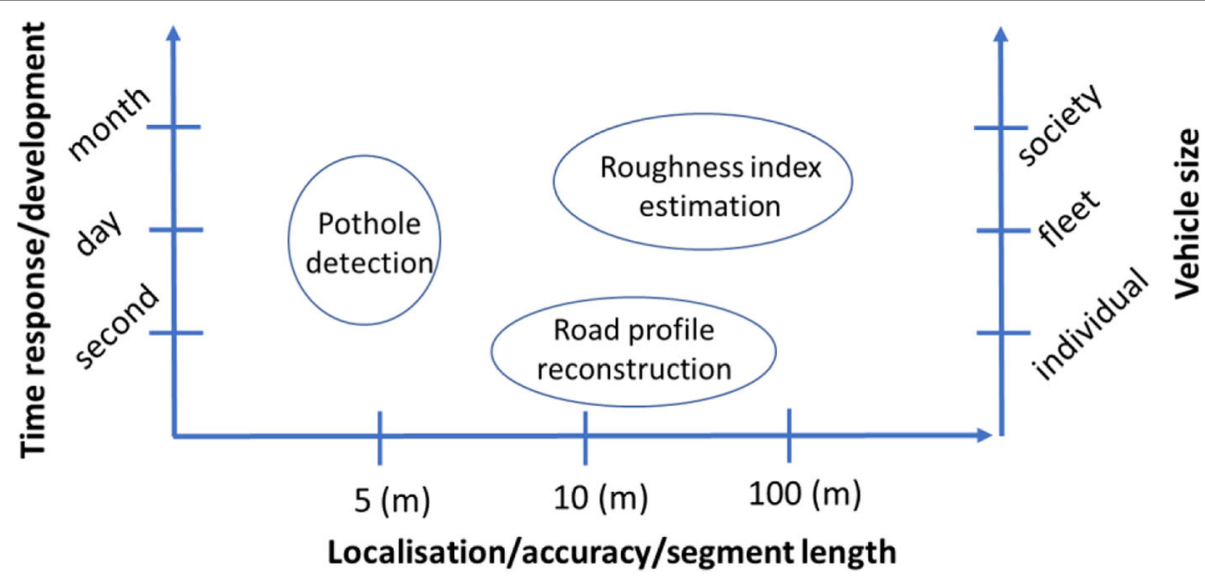

Fig. 1 Three temporal-spatial functions using response-based methods 


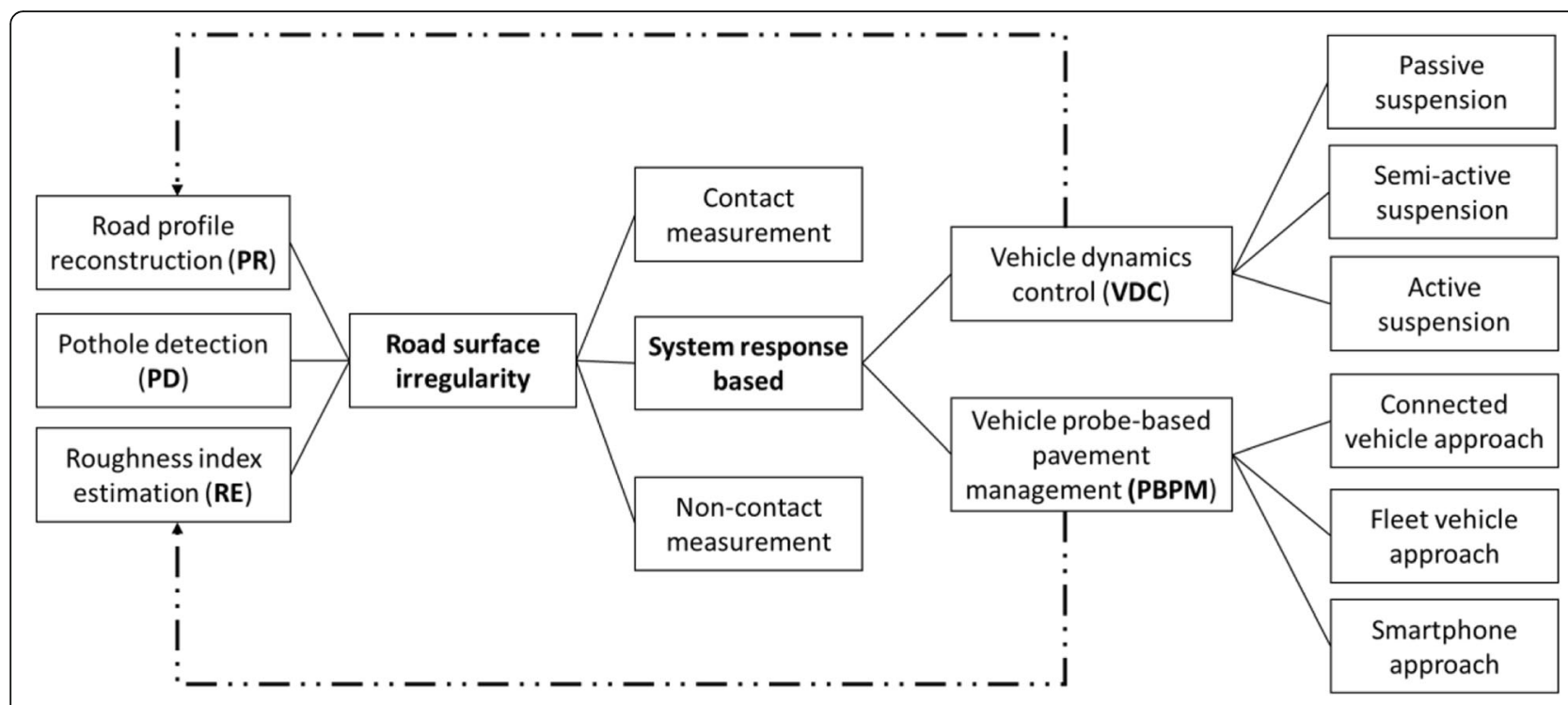

Fig. 2 Classification of different approaches to measure road surface irregularity under three main functions

\section{Literature data retrieval method}

Available articles regarding response-based methods to measure road surface condition were collected mainly from "Scopus" database [13] and partially from "Google Scholar" [14]. Articles of focus are those published by international journals and high-quality conferences. The first round of online search was conducted using the following keywords: (("road roughness" OR "road profile" OR "pothole") AND (accelerometer OR response) AND (estimation OR classification OR detection)) AND PUBYEAR > 2005, using Scopus' default search settings: article titles, abstracts and/or keywords. The search period is limited to the recent 15 years since an initial investigation found that studies on the topics mostly started at around 2006, with predominant numbers in the past 10 years (see Fig. 3b).
A total of 161 documents were obtained from the various field of studies, of which 86 are published journal articles, 3 are articles in press, 1 is a book chapter and 71 are conference papers. All retrieved documents were further analysed in which 87 documents were removed as being insufficiently related to the main scope of VDC or PBPM nor the main functionalities of system responsebased estimation (PR, PD or RE); these rejected documents are mostly related to bridge-vehicle interaction. Relevant references (56) were retrieved and included in the analysis (see Fig. 3a). The additional literature that was missed in the direct search is due to various technical terms being used in these documents such as road anomaly, abnormal section, impact, defect, bump, irregularity, failure, damage (instead of 'pothole') or sensing, measurement (instead of estimation, classification, detection). Among the 130 reviewed documents, 37\% are for road a

SCOPUS $=161$

Response-based methods to measure road roughness

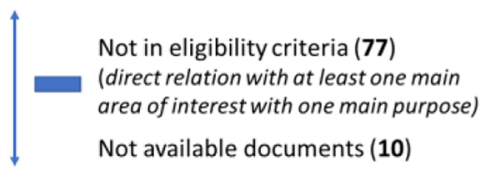

Core papers selected $=74$

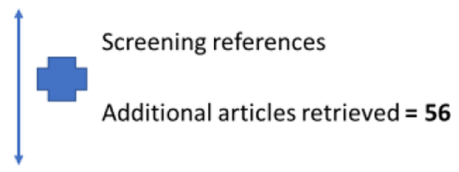

Total articles included $=130$ b

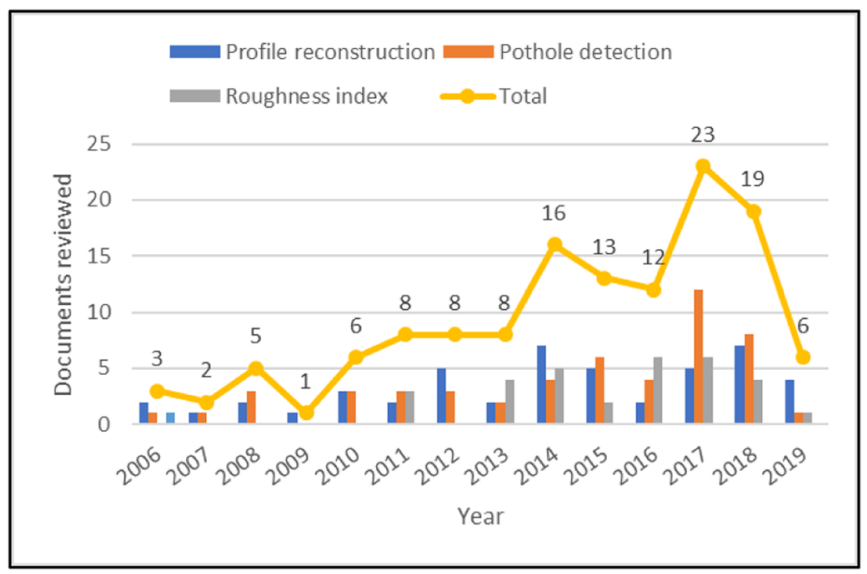

Fig. 3 Reviewed documents from (a) retrieval of 130 articles, and (b) development by years 
profile reconstruction, 39\% for pothole detection and the remaining $24 \%$ for roughness index estimation.

\section{Results}

\subsection{Road profile reconstruction/estimation for vehicles} dynamics control

Profile reconstruction/estimation (PR) is essential for vehicle dynamics control (VDC). However, control algorithms are dependent on vehicle suspension types, be it passive, semi-active or active, to formulate the corrective dynamics behaviours [15]. PR algorithms for VDC can be classified into three main approaches: 1) model-based methods or observers/estimators, 2) data-driven methods/ machine-learning techniques, and 3) frequency response functions/transfer functions and others. These are described in the following sections.

\subsubsection{Model-based methods (observers/estimators)}

Kalman filter/estimator (KF) and sliding mode observer (SM) are the most commonly-used methods since a long time. Three standard KFs are the linear KF for linear cases, the extended KF for a non-linear relationship, and the unscented KF for strong nonlinearities. Initially in 2011, the linear quarter-car model was developed to implement the KF method [16] that needed measurements of the suspension deflections, the body position and acceleration. In [17], an improved KF was developed to include the vehicle sprung mass change, and in [18] an augmented KF was developed to make use of all the available sensors. The PR is implemented with the modified KF framework in [19] for the non-linear spring-damper system to localise autonomous vehicle position. Unfortunately, for all KF methods, the tuning of the covariance matrix is usually done heuristically which effects the estimation results caused by the deterioration and loss of information. To overcome this drawback, an algebraic estimator was developed in [20], by updating the covariance matrix according to the change of road roughness [21], or by applying the adaptive KF and adaptive super-twisting observer (AKFASTO) algorithm in a new estimator [22].

Regarding other observer approaches, the most common method is the sliding mode observer (SM) considering the road profile as unknown inputs to be estimated. A 16DOF full-car model was firstly used to develop the SM based on the vertical motion of the vehicle [5]. A researcher [23] then developed a second-order SM to avoid the assumption of constant velocity, while another modelbased observer was developed to compensate for the chassis dynamics for minimising its interaction effect [6]. The higher-order SMs using adaptive super-twisting observer based on a nonlinear quarter-car model were also developed in [24] for PR, and in [25] for PR and tyre friction estimation simultaneously. The combination of sliding mode observer and adaptive Kalman filter for PR related to tyre dynamics can be found for active suspension control in [26]. Other methods of control theory using an adaptive observer with the Q-parameterisation method have shown their validity and feasibility [27] and the extensions in $[28,29]$ with detailed synthesis and experimental validation. Compared to other methods such as KF, the Q-parametrization method provides better performance and is suitable for real-time implementation due to less computing cost and implementation complexity.

Another state observer can be found in [30] to use the overall response of the preceding vehicle(s) to generate preview controller information for follower vehicles. An $\mathrm{H}_{\infty}$ observer was adopted and found to be feasible for real-time implementation but required knowledge of many vehicle parameters [31], while a jump-diffusion process estimator can perform PD and PR simultaneously [32]. Although these types of estimators can work effectively for active suspension system control, extensive modelling is required as the main drawback as well as the problem of speed variation.

\subsubsection{Data-driven methods/machine-learning techniques}

The emergence of machine-learning techniques (MLs) has motivated researchers to focus on various ML algorithms to measure road surface irregularity, as reported in more than half of the reviewed documents. Among them, Neural Network (NN)/Artificial Neural Network (ANN) and Support Vector Machine (SVM) are the most common methods. In 2010, a study [33] used a Bayesianregularised nonlinear autoregressive exogenous model (NARX) for PR based on the acceleration from a linear half-vehicle model. The ANN-based methodology has been applied for road surface condition identification on mining vehicles and mining roads [34], and for the Land Rover Defender 110 [35]. Similar ANN can be found in [36] using seven vehicle acceleration variables as inputs. To improve estimation efficiency, different techniques/algorithms have been implemented along with ANN. In [8], wavelet analysis was included in similar ANN for the connected vehicle environment. In [37], ANN was used with the mean square of unsprung mass acceleration divided by vehicle speed to classify road Power Spectral Density (PSD) regardless of vehicle speed and suspension parameters.

To classify different road types/terrains (e.g. brick, gravel, grass), ANN and principal component analysis (PCA) were used in combination with image processing [38], or SVM with PCA [39]. To remove the speed dependence from terrain classification, SVM was combined with wavelet analysis of acceleration data [40], or SVM with spatial frequency component analysis by Fast Fourier Transform [41].

Apart from ANN and SVM, other sophisticated MLs were developed and often combined with other techniques for 
VDC. Deep Neural Networks [42] and Probabilistic Neural Network classifier [43] were proposed by using measurable system responses. The Adaptive Neuro-Fuzzy Inference System - ANFIS road classification method was proposed using wavelet analysis based solely on sprung mass acceleration [44]. ANFIS classifier was found to be better than other methods in [45], and ANFIS was combined with KF for VDC of semi-active suspension in [21, 46]. PNN classifier using wavelet analysis showed better performance than ANFIS and NARX methods. The combination with PNN classifier and AKF-ASTO [22] adaptively changes the process noise covariances $\mathrm{Q}$ and $\mathrm{R}$ for the $\mathrm{KF}$, resulted in higher accuracy than existing KF method. Random forest classifier (RF) was used to combine information from both time and frequency domains for a controllable suspension system in [2], while the RF was combined with transfer function to develop a speed independent road classification strategy in [47]. Most recently, independent component analysis as a simple and fast method was developed in [48], and various MLs were compared in [49].

\subsubsection{Transfer functions and other techniques}

The transfer function (TF) was first used by Gonzalez in 2008 [50] to estimate road PSD based on the relationship between the road surface and vehicle acceleration via a TF as Eq. 1:

$$
H(\Omega)=P S D_{a c c}(\Omega) / P S D_{\text {road }}(\Omega)
$$

where $\operatorname{PSD}_{\mathrm{acc}}(\Omega)$ and $\operatorname{PSD}_{\text {road }}(\Omega)$ are the PSD for a frequency $\Omega$ due to vehicle accelerations and road profile, respectively.

The road can be classified according to ISO 8608 [51] based on $\mathrm{PSD}_{\text {road }}$ estimated from the $\mathrm{PSD}_{\mathrm{acc}}$ of the axle or body acceleration measurements [50]. In [52], similar results have confirmed the efficiency of the TF approach, and in [53] the TF was extended to a full-vehicle model to estimate road PSD regardless of vehicle speeds. From another point of view, dynamic tyre pressure sensor was used to estimate road profiles based on an assumption of a linear relationship between road surface profiles and tyre pressure via a TF [54].

Regarding other methods, a numerical optimisation technique can be found in [55] that employs Monte Carlo simulations to obtain the optimal PR, but it is costly for computing. The method of control-constraints was proposed [56] that focuses on tyre dynamics and requires solving differential-algebraic equations. A modulating function technique [57] can fulfil the real-time and noise suppression requirements with the focus particularly on off-road vehicles. In [58], Bayesian estimator was proposed regardless of vehicle models; but a priori information of the road is required. In addition to acceleration measurements, PR can be done by microphones to measure tyre noise [59]; however, a robustness study is needed to reduce signal contaminations.

\subsubsection{Summary of methods for road profile reconstruction/ estimation}

Table 1 lists the related model-based methods where most of them use a passive suspension system and quarter-vehicle model while fewer use active suspension system. Q-parameterisation has demonstrated its better performance than other methods, with less parameter information required after experimental validation using passive, semi-active and active suspension systems. The pothole detection does not gain much research interest with only 2 relevant studies. Studies on data-driven methods are listed in Table 2 and similarly most studies use a passive suspension system and quarter-vehicle model. Together with road profile reconstruction, the functions of pothole detection (2 studies), roughness index estimation (1 study) or terrain classification (4 studies in which 3 are from the same first author) can be found. Since the first ML emerging from NARX in 2010, recent research continues to improve the algorithms by increasing estimation accuracy and using less parameter information such as the ANFIS (only sprung mass). Research related to speed independence has shown the potential for large-scale application with both offline-online phase classification steps such as the speed independent road classification strategy - SIRCS. Studies on transfer function and other methods are listed in Table 3 for road profile reconstruction only without consideration of pothole detection or roughness index estimation, in which all the algorithms were developed using the passive suspension system. The sophisticated modelling of other methods has negated them from the real-time or online application.

In summary, various methods have been developed for PR (48 studies) and several include additional functions for PD (4/48 or $8.3 \%)$ and $\operatorname{RE~(1/48~or~} 2 \%)$, in which TF and other methods have focused on PR (9/48 or $19 \%$ ) only (see Fig. 4). A high number of studies use quarter-vehicle model $(29 / 48$ or $60 \%)$ and passive suspension system (32/48 or $67 \%)$, in which TF and other methods mostly use passive system $(8 / 9$ or $89 \%)$. Starting from the first developed Kalman filter, sliding mode observer, artificial neural network and transfer function methods in the 2010s which require many vehicle parameters but fewer accuracy levels, recent methods are focusing on fast computation with fewer parameters for online and real-time application. The combination of different techniques has resulted in higher estimation performance such as machine learning and feature extraction, or machine learning and Kalman filters. 
Table 1 Summary of model-based methods for road profile reconstruction function

\begin{tabular}{|c|c|c|c|c|c|c|c|c|c|}
\hline \multirow{2}{*}{$\begin{array}{l}\text { System } \\
\text { name/ } \\
\text { by }\end{array}$} & \multirow[t]{2}{*}{ Model-based approach } & \multirow[t]{2}{*}{ Additional } & \multicolumn{3}{|c|}{ Suspension } & \multicolumn{3}{|c|}{$\begin{array}{l}\text { Vehicle } \\
\text { model }\end{array}$} & \multirow[t]{2}{*}{ Main parameter } \\
\hline & & & $\mathrm{P}$ & SA & A & Q & $\mathrm{H}$ & $\mathrm{F}$ & \\
\hline [16] & KF & & $\checkmark$ & & & $\checkmark$ & & & body position and acc, suspension def \\
\hline [17] & improved KF & & $\checkmark$ & & & $\checkmark$ & & & sprung acc, suspension def \\
\hline [18] & augmented KF & & $\checkmark$ & & & $\checkmark$ & & $\checkmark$ & suspension dis, unsprung, sprung acc \\
\hline [19] & modified KF & & $\checkmark$ & $\checkmark$ & & $\checkmark$ & $\checkmark$ & $\checkmark$ & vertical dis of the tire-road contact points, longitudinal acc \\
\hline$[5,23]$ & SM, second-order SM & & $\checkmark$ & & & & & $\checkmark$ & wheels and chassis \\
\hline [6] & SM & PD & $\checkmark$ & & & $\checkmark$ & & & chassis \\
\hline [24] & higher-order SM & & & & $\checkmark$ & $\checkmark$ & & & sprung mass dis and velocity \\
\hline [25] & higher-order SM & & & & Tyre & $\checkmark$ & & & $\begin{array}{l}\text { random road profile, the longitudinal friction force, and the } \\
\text { engine friction }\end{array}$ \\
\hline [26] & $\mathrm{SM}+\mathrm{AKF}$ & & & & Tyre & $\checkmark$ & & $\checkmark$ & spring def, wheel acc, tire road contact acc \\
\hline [27] & Q-parametrization & & & & $\checkmark$ & $\checkmark$ & & & sprung mass position \\
\hline [28] & Q-parametrization & & & $\checkmark$ & & $\begin{array}{l}\boldsymbol{J}(1 / \\
5)\end{array}$ & & & \\
\hline [29] & Q-parametrization & & $\checkmark$ & & & $\checkmark$ & & & \\
\hline$[20,30]$ & $\begin{array}{l}\text { Algebraic estimator, state } \\
\text { observer }\end{array}$ & & $\checkmark$ & & & $\checkmark$ & & & sprung mass and unsprung mass vertical dis, suspension def \\
\hline [31] & Ho observer & & & & $\checkmark$ & $\begin{array}{l}\boldsymbol{J}(1 / \\
5)\end{array}$ & & & sprung acc, suspension def, unsprung mass motion \\
\hline [32] & Jump-diffusion estimator & PD & $\checkmark$ & & & & $\checkmark$ & & wheel excitation \\
\hline
\end{tabular}

Table 2 Summary of data-driven methods for road profile reconstruction function

\begin{tabular}{|c|c|c|c|c|c|c|c|c|c|}
\hline \multirow[t]{2}{*}{ System name/by } & \multirow[t]{2}{*}{ Machine learnings } & \multirow[t]{2}{*}{ Additional } & \multicolumn{3}{|c|}{ Suspension } & \multicolumn{3}{|c|}{ Vehicle model } & \multirow[t]{2}{*}{ Main parameter } \\
\hline & & & $P$ & SA & $\bar{A}$ & Q & $\mathrm{H}$ & $\mathrm{F}$ & \\
\hline [33-35] & ANN (NARX) & $P D$ & $\checkmark$ & & & & $\checkmark$ & & sprung, axle, body \\
\hline [36] & ANN & & $\checkmark$ & & & & & $\checkmark$ & wheels and chassis \\
\hline [8] & ANN + wavelet DWT) & $\mathrm{RE}(\mid \mathrm{RI})$ & $\checkmark$ & & & $\checkmark$ & & & sprung mass \\
\hline [37] & $A N N+A D V$ & & $\checkmark$ & $\checkmark$ & & & & $\checkmark$ & unsprung mass \\
\hline [38] & ANN + image processing + PCA & Terrain & $\checkmark$ & & & $\checkmark$ & & & wheel acc, speed \\
\hline [39-41] & SVM+ PCA, FWT, FFT & & & & & & & & \\
\hline DNNs classifier [42] & Deep NNs & & & $\checkmark$ & & & & $\checkmark$ & sprung, unsprung, rattle space \\
\hline PNN classifier [43] & PNN + WPT & & & $\checkmark$ & & $\checkmark$ & & & sprung, unsprung, rattle space \\
\hline ANFIS classifier [44] & ANFIS & & & $\checkmark$ & & $\checkmark$ & & & sprung mass \\
\hline [45] & ANFIS, RLS, GMDH & & & $\checkmark$ & & $\checkmark$ & & & sprung, unsprung, rattle space \\
\hline ANFIS+AKF [21] & ANFIS + Kalman filter & & & & $\checkmark$ & $\checkmark$ & & & sprung mass \\
\hline AKF-ASTO [22] & PNN + Kalman filter & & & & & $\checkmark$ & & & sprung, unsprung \\
\hline [46] & ANFIS + MOOP + NSGA-II & & & $\checkmark$ & & $\checkmark$ & & & sprung mass \\
\hline [2] & $R F+W P T$ & & & & $\checkmark$ & $\checkmark$ & $\checkmark$ & & sprung, unsprung, speed \\
\hline SIRCS [47] & $\mathrm{RF}+\mathrm{TF}$, decision procedure & & $\checkmark$ & & & $\checkmark$ & & & unsprung mass \\
\hline [48] & Independent Component Analysis & & $\checkmark$ & & & $\checkmark$ & $\checkmark$ & $\checkmark$ & chassis, suspension \\
\hline [49] & Various MLs + TF & PD & $\checkmark$ & & & & & $\checkmark$ & axle or body, speed \\
\hline
\end{tabular}

PCA, WPD, WPT, DWT, FWT: Principal Component Analysis, Wavelet Package Decomposition, Wavelet Package Transformation, Discrete Wavelet Transform, Fast Wavelet Transform.

RLS, GMDH, ADV: Recursive Least Square, Group Method of Data Handling, the mean square of unsprung mass acceleration divided by vehicle speed. 
Table 3 Summary of TF and other methods for road profile reconstruction function

\begin{tabular}{|c|c|c|c|c|c|c|c|c|}
\hline \multirow{2}{*}{$\begin{array}{l}\text { System } \\
\text { name/ } \\
\text { by }\end{array}$} & \multirow[t]{2}{*}{ TF and others } & \multicolumn{3}{|c|}{ Suspension } & \multicolumn{3}{|c|}{ Vehicle model } & \multirow[t]{2}{*}{ Main parameter } \\
\hline & & $P$ & SA & A & Q & $\mathrm{H}$ & $\mathrm{F}$ & \\
\hline [50] & TF & $\checkmark$ & & & & $\checkmark$ & & axle or body \\
\hline [52] & TF & $\checkmark$ & & & $\checkmark$ & & & unsprung mass acceleration \\
\hline [54] & TF & $\checkmark$ & & & & & & tyre pressure \\
\hline [53] & TF + time span & $\checkmark$ & & & & & $\checkmark$ & axle or body \\
\hline [55] & Cross-entropy & $\checkmark$ & & & & $\checkmark$ & & sprung and unsprung acc \\
\hline [56] & Control-constraints & $\checkmark$ & & & & & $\checkmark$ & tire dynamics \\
\hline [58] & Bayesian parameter & & & & & & & rear wheel acc, veh response, speed \\
\hline [59] & Microphone & $\checkmark$ & & & $\checkmark$ & & & tyre noise and axle acc \\
\hline [57] & Modulating function technique & $\checkmark$ & & & & & $\checkmark$ & accelerometer, spring dis and orientation \\
\hline
\end{tabular}

\subsection{Pothole detection and roughness index estimation}

The three approaches in PBPM has been classified as: connected vehicle approach (uses OEM-installed accelerometers, sensor hardware and standardised onboard vehicle) fleet vehicle approach (uses semi-permanent, non-stock accelerometers in a fleet of agency-owned vehicles, supplemented by GPS units) and mobile device approach (uses accelerometer-equipped mobile devices to gather and transmit roughness information to a central database) [9]. The latter approach using smartphone sensors as the concept of "citizen as sensors" in [60] or "citizen engineer" [61] has received much research interest in recent years, followed by the connected vehicle and the fleet vehicle (which can be grouped into one dedicated sensor onboard approach). Regardless of applications, the methodology can be classified into three groups: acceleration thresholds or threshold-based methods, signal processing and machinelearning techniques.

\subsubsection{Threshold-based methods}

Threshold-based methods are the most straightforward approaches for PD detection by processing mainly the vertical acceleration (Z-acc) or in combination with

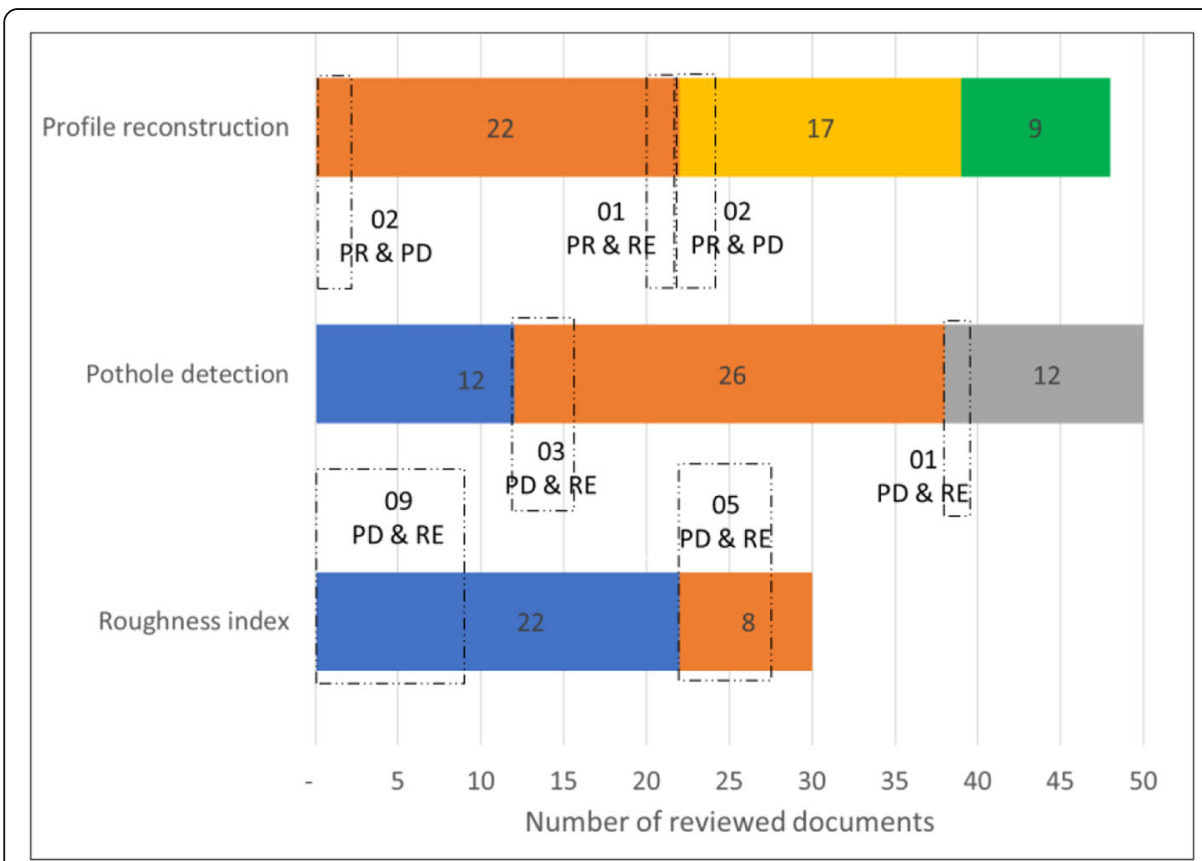

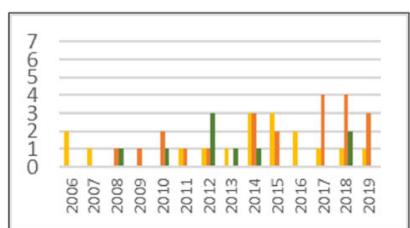

Profile reconstruction

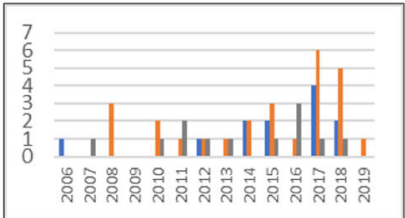

Pothole detection

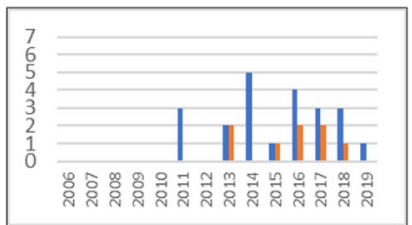

Roughness index estimation
Signal processing

nodel-based methods
Data-driven/Machine learning " Threshold-based

- TF and others

Fig. 4 Method classification for RE, PD and PR 
other direction acceleration ( $\mathrm{x}$ and $\mathrm{y})$ and gyroscopes. A researcher [62] has proposed four indices in which the Z-THRESH was further modified [63] to build a cloud computing system: Z-THRESH (from vertical vibration), Z-DIFF (from the difference of consecutive Z-acc above threshold), STDEV(Z) (as the standard deviation of Zacc above threshold in a window), and G-ZERO (whether the sensor senses a $0-G$ vibration). Similar $\operatorname{STDEV}(Z)$ can also be found in [64] and to develop a bump index in [65]. Other acceleration thresholds are used to classify three relative rough road levels [66] or severity levels of potholes $[67,68]$ and to characterise road bumps [69]. Thresholds of Z-acceleration and ultrasonic data were combined in [70] while the Z-jerk as the "rate of change of acceleration" is used in Cyberphysical system [71]. However, how to set up correct thresholds is challenging under the influence of vehicle speeds, suspension parameters as well as sensor location and orientation. Furthermore, only pothole detection alone is not sufficient for real application, as transport authorities care about roughness index estimation as well for road surface maintenance.

\subsubsection{Signal processing}

To overcome the drawbacks of the threshold-based methods, various signal processing filters have been used. Researcher [72] further processed Z-acc by simple filters and Gaussian model-based algorithm to detect the severity of potholes and differentiate humps and potholes. A study in [73] combined Z-THRESH and G-ZERO and adopted a spatial interpolation method to obtain precisely pothole locations. Fuzzy logic was used to detect and recognise the speed bumps from vehicle speed and Z-acc variance [74]. Time-frequency analysis was used such as the Discrete Wavelet Transform to estimate gravel roads ride quality, detect the location and the severity of surface potholes [75], or the Gabor transform to estimate road roughness condition in combination with image processing for PD [76]. In [77], a greedy heuristic approach for an optimal mobile sensor placement maximises the total length of the road inspected by sensors.

Frequency filter, speed filter and small peaks filter were used to develop the vertical acceleration impulse that corresponds to a "high-energy event" on the road surface in UNIquALroad $[78,79]$. Dynamic Time Warping - DTW detects pothole by using the pattern-matching technique independent of time and speed [80]. Similar to DTW, the Smartphone Probe Car system was developed using a new road anomaly indexing heuristic which is adaptive to vehicle dynamics [81].

To evaluate road roughness IRI, the well-known regression relationships between PSD with IRI was investigated in $[82,83]$, so do the root-mean-squared acceleration (RMS) and IRI in $[84,85]$. A compact road profiler and ArcGIS to measure and evaluate road roughness condition was introduced in [86]. Filter and Fast Fourier Transform (FFT) were used to estimate IRI from smartphone data under realistic setting (e.g. inside pockets) based on the approximate proportion of spectrum magnitude and road IRI $[87,88]$. The inverse pseudo-excitation method offers a new approach to estimate IRI independent of the travelling speed, road roughness grade, and vehicle type [89]. The RMS acceleration was further studied to detect potholes using speed filter and Z-axis filter in Pothole Patrol, and to develop new roughness index (IRI-proxy) depicting overall road quality [60]. Based on the relationship of PSD between road surface and vertical acceleration, parameters of road profile can be evaluated using Maximum Likelihood-based estimation [90], or using linear predictive coding by averaging the power of the prediction error [91, 92]. In [93], a recursive multiscale Correlation-Averaging algorithm was developed to deal with the uncertainty/noise such as GPS inaccuracies, driving path variation and errors from the distancemeasuring devices.

Regarding new roughness index, a speed-independent road impact factor - RIF (individual vehicle) and its corresponding time-wavelength-intensity-transform - TWIT (vehicle groups) for connected vehicles were established using advanced signal processing in [94]. Further studies were conducted intensively to investigate and validate the RIF regarding sampling rate selection [95], localisation [96, 97], RIF-IRI proportionality [98], deterioration forecasts in consideration of suspension parameter variances [99], stop-andgo conditions [100], and wavelength sensitivity [101].

\subsubsection{Machine learning techniques}

With more data availability, machine learning techniques (MLs) have been utilised in PD and RE functions while noting that most of them were developed for the PD. The abovementioned Z-THRESH is similar but simpler than Zpeak in Pothole Patrol [102], Nericell [103] and TrafficSense [104], which used specific algorithms to filter and to cluster the collected data. Based on Pothole Patrol, further analysis to differentiate pothole and bump-road cases in [105], or to develop the PRISM platform for remote sensing [106]. For the same purpose, a supervised learning approach based on temporal classification was undertaken in [107]. Based on Pothole Patrol, $\mathrm{P}^{3}$ can infer the depth and length of the pothole by adopting a one degree-of-freedom (DOF) vibration model as well as perform a self-learning vibration recovery algorithm [108]. A clustering ML was used to cluster potholes with an adaptive detection threshold and learning rate update in CRSM $[109,110]$ after using pothole filters in Pothole Patrol. K-mean clustering was used in [111] and additional Random Forest (RF) classifier in [112]. Another study [113] developed an online road roughness classification system using bicycles 
instrumented with smartphones embedded with the K-Nearest-Neighbour and Naive Bayes algorithm.

Among MLs, support vector machine (SVM) is used most frequently, and it is often combined with feature extraction methods as multiple classifiers. In [114], SVM was used to detect road anomalies by processing the data collected from a motorcycle-mounted tri-axial accelerometer and further classify road surface condition using unsupervised ML. Recently, SVM and Dynamic Time Warping algorithm were developed in [115] to identify aggressive driving events, road bumps and potholes for cycling. Another improvement was included in [116] where the gyroscope around gravity rotation was used. SVM and wavelet analysis were also used in RoADS [117] to classify the road anomaly into three event classes: severe, mild and span, and in [118] to detect road anomaly based on driver attitudes toward the speeds and turnings. SVM and Fast Fourier Transformation were used in [119] to remove the speed dependence and to label road anomaly. Another study in [120] combined SVM and Wavelet Package Decomposition to detect potholes with low computing cost. In Wolverine [121], the smartphone accelerometer data is used to detect braking events and bumps using $\mathrm{K}$-means clustering and SVM. In [122, 123], SVM was trained using extensive data set from CarSim vehicle simulation as well as experiment, applying for under-sampled vehicles sensor problems and multi-lane pothole detection. In [124], a virtual road network inspector was built based on SVMs to detect potholes using accelerometers mounted to the front and rear axles of the buses.

The comparison of different MLs was conducted in several studies to find the best ML. In [125], a data mining approach was developed to compare the performance of five algorithms for PD. By adopting the framework of this study, a study [126] used RF for its best performance to develop a cloud-based Road Anomaly Service architecture in which PCA was used for feature extraction. PCA was also used in $[127,128]$ after NN and RF classification were compared to develop a street defect classifier to select NN for its better performance. RMS thresholds were set as a triggering condition for data logging condition and a new street defect level (from 0 to 1 ) to evaluate the road segment condition. In RoadSense [129], Decision Tree (DT) was designed and compared with SVM and Naïve Bayes algorithm after feature extraction. In Pothole lab [130], a new $\operatorname{SVM}(Z)$ and Swarm indices were developed to compare with the four thresholds in [62], Nericell, Pothole Patrol, and PERT [119]. Backward feature elimination was used in [131] to select the optimal set of features for different classification models while in [132] the forward selection and backwards elimination process was performed showing better performance than existing approaches.

Besides CRSM system for IRI estimation, MLs were used in [133] where the authors used smartphone sensor data for training a feature-based prediction model and compared with the road condition from official IRI measurements of the road surface. Another researcher [134] applied NARX ANN to estimate IRI from the connected vehicle after investigating vehicle suspension characteristics and its speed in [8]. In [7], the mean-absolute-value of the Z-acc for every $100 \mathrm{~m}$ was sensed by a smartphone on a motorbike, and a fuzzy classifier from a server was used for RE.

\subsubsection{Summary of methods for pothole detection and road roughness estimation}

Studies on threshold-based methods are listed in Table 4. Given the simplicity of this method based on true positive and false positive of the detection rate, the threshold values may vary due to different factors which make this method not being feasible to be used in real scenarios and large-scale implementation. Table 5 lists the studies on signal processing methods, in which not only the methods of accurate PD and RE but also further concerns on GPS data noise/inaccuracy, sensor and smartphone installation/direction, data fusion/aggregation and crowdsensing system/platform were considered. Among them, the adaptive thresholds in Smartphone Probe Car and Smart patrolling, as well as the IRI-proxy, SmartRoadSense and UNIquaALroad system are found to be promising for large scale application. RIF and TWIT are also potential replacements of IRI in the context of connected vehicle environments. As for $M L$ methods recent studies are listed in Table 6. MLs have attracted many studies resulting in high performance in which PCA plays an important role in feature extraction for the training process. CRSM $[109,110]$, the system in $[122$, 123] and another in [133] are promising systems for large scale application.

In summary, the diversity of methods and systems have been described in over 80 reviewed articles for the main functions of PD (50/80 or 63\%) and RE (30/80 or 27\%). Many algorithms can perform both PD and RE (20/80 or $20 \%)$. The same number of studies use MLs and signal processing (34 each or 41\%) whereas threshold-based methods are used mostly for PD (8\%). MLs received more research interest than other methods for PD (26/50 or $52 \%)$. In contrast, signal processing is preferred for RE (22/30 or $73 \%)$ especially for IRI estimation, in which $11 / 22$ studies (50\%) are original algorithms while others are further development or application (Fig. 4). Over the studies related to RE, 6/30 $(20 \%)$ is about the relative roughness index, $14 / 30$ (47\%) for IRI estimation, 2/30 (7\%) for IRI-proxy estimation 
Table 4 Summary of threshold-based methods for pothole detection and roughness index estimation

\begin{tabular}{|c|c|c|c|c|c|c|}
\hline \multirow[t]{2}{*}{ System name/by } & \multirow[t]{2}{*}{ Thresholds } & \multicolumn{2}{|c|}{ Function } & \multicolumn{3}{|c|}{ Approach } \\
\hline & & PD & RE & $C$ & $\mathrm{~F}$ & $S$ \\
\hline$[62],[63]$ & Z-thresh, Z-diff, Stdev(z), G-zero & $\checkmark$ & & & & $\checkmark$ \\
\hline BusNet [64] & std of filtered Z-acc & $\checkmark$ & & & $\checkmark$ & \\
\hline Bump Recorder [65] & Z-acc, bump index & $\checkmark$ & & & & $\checkmark$ \\
\hline [66] & Z-acc & $\checkmark$ & Relative & & & $\checkmark$ \\
\hline Smart Pune [67] & Z-acc, skid, accident, braking & $\checkmark$ & & $\checkmark$ & & \\
\hline [68] & Z-acc for severity levels & $\checkmark$ & & & & $\checkmark$ \\
\hline [69] & Z-acc pattern & $\checkmark$ & & & & $\checkmark$ \\
\hline Cyber-physical system [71] & Z-jerk & $\checkmark$ & & & & $\checkmark$ \\
\hline [135] & $0.1 \mathrm{~g}$ threshold & $\checkmark$ & & & & $\checkmark$ \\
\hline PoDAS [70] & Z-acc, ultrasonic & $\checkmark$ & & $\checkmark$ & & \\
\hline
\end{tabular}

Relative: Pothole-based roughness index.

and $8 / 30(27 \%)$ for the new roughness index (RIF and TWIT). There are only 6 studies $(7 \%)$ related to fleet vehicle approach, 23 studies for the connected vehicle $(28 \%)$ and 53 studies for smartphone approach (65\%). The problems of GPS accuracy, data aggregation and crowdsourcing have been considered in many studies using signal processing (9/21 studies) and ML (13/30 studies), aiming at supporting the emergence of crowdsourcing-based road surface monitoring.

\section{Discussion, conclusion and outlook}

Different methods present different levels of complexity, precision and computing intensiveness. Across all the

Table 5 Summary of signal processing methods for pothole detection and roughness index estimation

\begin{tabular}{|c|c|c|c|c|c|c|c|c|c|}
\hline \multirow[t]{2}{*}{ System name/by } & \multirow[t]{2}{*}{ Signal processing } & \multicolumn{2}{|c|}{ Function } & \multicolumn{3}{|c|}{ Approach } & \multicolumn{3}{|c|}{ Additional } \\
\hline & & $\overline{P D}$ & RE & C & $\mathrm{F}$ & 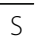 & GPS & Data & Crowd \\
\hline UNlquaALroad[78, 79] & high-energy events & $\checkmark$ & & & & $\checkmark$ & & $\checkmark$ & $\sqrt{\checkmark}$ \\
\hline Smart patrolling [80] & filter + DTW (adaptive) & $\checkmark$ & & & & $\checkmark$ & & $\checkmark$ & $\checkmark$ \\
\hline Smart Probe Car [81] & $\begin{array}{l}\text { anomaly index heuristic } \\
\text { (adaptive Al) }\end{array}$ & $\checkmark$ & & & & $\checkmark$ & $\checkmark$ & $\checkmark$ & $\checkmark$ \\
\hline [72] & Z-acc, Gaussian model & $\checkmark$ & & & & $\checkmark$ & & & \\
\hline [73] & Z-thresh, G-zero combined & $\checkmark$ & & & & $\checkmark$ & & $\checkmark$ & \\
\hline [74] & Fuzzy logic & $\checkmark$ & & & & $\checkmark$ & & & \\
\hline$[75,76]$ & time-frequency analysis & $\checkmark$ & & & & $\checkmark$ & & & \\
\hline [77] & Greedy heuristic algorithm & $\checkmark$ & & & $\checkmark$ & & $\checkmark$ & $\checkmark$ & \\
\hline [90] & Maximum Likelihood-based & $\checkmark$ & & $\checkmark$ & & & & & \\
\hline RCM-TAGPS $[82,83]$ & PSD + empirical formula & & $|\mathrm{R}|$ & $\checkmark$ & & & & & \\
\hline [84] & RMS acceleration & & $|\mathrm{R}|$ & $\checkmark$ & & & & & \\
\hline [85] & RMS acceleration & & $|\mathrm{R}|$ & & & $\checkmark$ & & & \\
\hline STAMPER [86] & filter + IRI & & $|\mathrm{R}|$ & $\checkmark$ & & & & & \\
\hline$[87,88]$ & Filter + FFT & & $|\mathrm{R}|$ & & & $\checkmark$ & & & \\
\hline IPEM [89] & Inverse pseudo-excitation method & & $\mid \mathrm{RI}$ & $\checkmark$ & & & & & \\
\hline [60] & |RI-proxy & $\checkmark$ & |RI-proxy & & & $\checkmark$ & & $\checkmark$ & $\checkmark$ \\
\hline $\begin{array}{l}\text { SmartRoad } \\
\text { Sense } \\
{[91,92]}\end{array}$ & $\begin{array}{l}\text { PSD + Linear } \\
\text { Predictive Coding }\end{array}$ & & Relative & & & $\checkmark$ & $\checkmark$ & $\checkmark$ & $\checkmark$ \\
\hline [93] & Correlation-Averaging Algorithm & $\checkmark$ & $\checkmark$ & $\checkmark$ & & & $\checkmark$ & $\checkmark$ & \\
\hline $\operatorname{RIF}[95-101]$ & RIF-transform, TWIT & $\checkmark$ & New & $\checkmark$ & & & $\checkmark$ & $\checkmark$ & \\
\hline
\end{tabular}


Table 6 Summary of ML methods for pothole detection and roughness index estimation

\begin{tabular}{|c|c|c|c|c|c|c|c|c|c|}
\hline \multirow[t]{2}{*}{ System name/by } & \multirow[t]{2}{*}{ Machine learning } & \multicolumn{2}{|c|}{ Function } & \multicolumn{3}{|c|}{ Approach } & \multicolumn{3}{|c|}{ Additional } \\
\hline & & PD & RE & $C$ & $\mathrm{~F}$ & S & GPS & Data & Crowd \\
\hline Pothole Patrol [102] & Clustering + training detector & $\checkmark$ & & $\checkmark$ & & & & & \\
\hline Nericell [103], TrafficSense $[104,105]$ & Z-peak method/ Clustering + training detector & $\checkmark$ & & & & $\checkmark$ & & & \\
\hline PRISM [106] & Z-peak method + training detector & $\checkmark$ & & & & $\checkmark$ & & & $\checkmark$ \\
\hline [107] & supervised ML & $\checkmark$ & & & & $\checkmark$ & & & \\
\hline$P^{3}[108]$ & Clustering + training detector & $\checkmark$ & & & & $\checkmark$ & & $\checkmark$ & \\
\hline PADS [111] & K-mean clustering & $\checkmark$ & & $\checkmark$ & & & & & \\
\hline BDS [112] & K-means clustering $+\mathrm{RF}$ & $\checkmark$ & & & & $\checkmark$ & & & \\
\hline [113] & Naive Bayes algorithm + K-nearest-neighbor & & Relative & & & $\checkmark$ & & & \\
\hline [114] & SVM + unsupervised ML & $\checkmark$ & Relative & & & $\checkmark$ & & & \\
\hline D\&Sense [115] & SVM + DTW & $\checkmark$ & & & & $\checkmark$ & & & $\checkmark$ \\
\hline $\begin{array}{l}\text { RoadMonitor [116], RoADS-based [117, } \\
\text { 118] }\end{array}$ & SVM, SVM + SWT & $\checkmark$ & & & & $\checkmark$ & & & \\
\hline [119] & SVM + FFT, cross validation & $\checkmark$ & & & & $\checkmark$ & $\checkmark$ & & \\
\hline [120] & SVM + WPD, feature selection & $\checkmark$ & & & & $\checkmark$ & & & \\
\hline Wolverine [121] & SVM + K-means clustering & $\checkmark$ & & & & $\checkmark$ & & & \\
\hline [122] [123] & $\begin{array}{l}\text { SVM + data filter, sliding window, greedy forward feature } \\
\text { selection }\end{array}$ & $\checkmark$ & & $\checkmark$ & & & $\checkmark$ & $\checkmark$ & $\checkmark$ \\
\hline VRNI [124] & SVM + filter, moving window, feature extraction & $\checkmark$ & & & $\checkmark$ & & & & \\
\hline CRISP-DM-based $[125,126]$ & various algorithms comparison & $\checkmark$ & Relative & & & $\checkmark$ & & & \\
\hline$[127,128]$ & various algorithms comparison & $\checkmark$ & Relative & $\checkmark$ & & & $\checkmark$ & $\checkmark$ & \\
\hline RoadSense [129], Pothole Lab [130] & various algorithms comparison & $\checkmark$ & & & & $\checkmark$ & & & $\checkmark$ \\
\hline [131] & various algorithms comparison & $\checkmark$ & & & & $\checkmark$ & & & \\
\hline [132] & various algorithms comparison & $\checkmark$ & & $\checkmark$ & & & & $\checkmark$ & \\
\hline CRSM [109, 110] & iGMM clustering & $\checkmark$ & $|\mathrm{R}|$ & & $\checkmark$ & & & $\checkmark$ & $\checkmark$ \\
\hline [133] & SVM + WPD, Random forest & & $|\mathrm{R}|$ & & & $\checkmark$ & $\checkmark$ & $\checkmark$ & $\checkmark$ \\
\hline [134] & ANN + feature selection & & $|\mathrm{R}|$ & $\checkmark$ & & & & $\checkmark$ & \\
\hline [7] & Fuzzy classifier & $\checkmark$ & Relative & & & $\checkmark$ & & $\checkmark$ & $\checkmark$ \\
\hline
\end{tabular}

Relative: Pothole-based roughness index;

ANN, SVM, RF, DT: Artificial Neural Network, Support Vector Machine, Random Forest, Decision Tree;

PCA, WPD, DWT: Principal Component Analysis, Wavelet Package Decomposition, Discrete Wavelet Transform.

reviewed documents and methods, it is recognised that data-driven methods/MLs are increasingly being used for all the functions in PR, PD and RE (see Fig. 4), as well as the usage of the passive suspension system and quarter-vehicle model due to their modelling simplification. Recent studies have shifted towards RE as shown in the time series graphs, in which signal processing techniques have been preferred for RE given the ability to achieve advanced functionalities such as adaptive thresholds or data fusion. Regarding the function of PR for the individual suspension system, it is more comprehensive to integrate PR for suspension control with variable uncertainty, but more challenges will occur on the knowledge of vehicle dynamic characterisation. Whereas to deal with PD and RE for group of vehicles (fleet or connected vehicle) and "citizen sensor" concept in the largescale society, the issues of GPS accuracy, data fusion (e.g. the aggregation of sensor data or vehicle suspension types) and crowdsourcing will be challenges to the development of appropriate algorithms/systems. So far, several established algorithms/systems have solved these issues successfully.

In summary, the development of response-based methods to evaluate road surface irregularity has attracted research interests from both automotive technology and pavement engineering, aiming at the three main functions of Road profile reconstruction (PR), pothole detection (PD) and roughness index estimation (RE). The review of about 130 articles on this topic has revealed the diversity of recent approaches mostly within the recent decade. At first, the present study describes the algorithms used for PR including model-based methods, data-driven methods, transfer functions and others. Then, related algorithms for $\mathrm{PD}$ and RE are described including the threshold-based, 
Table 7 Advantages and disadvantages of response-based methods

\begin{tabular}{|c|c|c|}
\hline Response-based methods & Advantages & Disadvantages \\
\hline \multicolumn{3}{|l|}{ 1. Road profile reconstruction } \\
\hline 1.1. Model-based approach & $\begin{array}{l}\text { can deal with unforeseen } \\
\text { situations that are not included } \\
\text { in the data-driven training datasets. }\end{array}$ & $\begin{array}{l}\text { - an accurate model is required } \\
\text { - not all required response } \\
\text { information is measurable } \\
\text { - often only time domains }\end{array}$ \\
\hline 1.2 Kalman filter/estimator & convenient, fast and simple & $\begin{array}{l}\text { - a priori information } \\
\text { about model errors } \\
\text { - the tuning of the } \\
\text { covariance matrix is } \\
\text { usually done heuristically }\end{array}$ \\
\hline 1.1.2 Observer & can include tyre dynamics & $\begin{array}{l}\text { generally required knowledge } \\
\text { of many vehicle parameters }\end{array}$ \\
\hline i. Sliding mode observer & - convergence of the errors & $\begin{array}{l}\text { rather complicated for } \\
\text { practical application }\end{array}$ \\
\hline ii. Q-parameterisation & $\begin{array}{l}\text { - less computing cost } \\
\text { and complexity for } \\
\text { real-time implementation } \\
\text { - better performance than KF }\end{array}$ & $\begin{array}{l}\text { - the problem of } \\
\text { extensive modelling } \\
\text { - the sensitivity to speed } \\
\text { variation in almost methods }\end{array}$ \\
\hline $\begin{array}{l}\text { iii. Algebraic estimator } \\
\text { iv. Ho observer } \\
\text { v. State observer } \\
\text { vi. Jump-diffusion }\end{array}$ & $\begin{array}{l}\text { - can work effectively in } \\
\text { the framework of the } \\
\text { active suspension system } \\
\text { - overcome the drawbacks of KF }\end{array}$ & \\
\hline 1.2 Data-driven approach (MLs) & $\begin{array}{l}\text { - can use fewer parameters } \\
\text { (e.g. only sprung or unsprung mass) } \\
\text { - various ML techniques to be applied } \\
\text { - does not require excessive } \\
\text { system characterisation } \\
\text { - required fewer analytical } \\
\text { skills than parametric model }\end{array}$ & $\begin{array}{l}\text { - impractical for an online } \\
\text { road estimation due to } \\
\text { computationally costly } \\
\text { training datasets (e.g. } \\
4655 \mathrm{~s} \text { are required to } \\
\text { train the } \\
\text { ANN-based moded) }\end{array}$ \\
\hline 1.2.1 Only MLs (e.g. ANN) & - able to detect potholes & $\begin{array}{l}\text { - spatial frequency only } \\
\text { - many vehicle parameters } \\
\text { - not high accuracy and } \\
\text { sensitivity to speed variation }\end{array}$ \\
\hline
\end{tabular}

1.2.2 Combined MLs and others

i. with feature selection

(e.g. WPT, FFT, PCA)

ii. with $\mathrm{KF}$

iii. with TF

1.3 Transfer function and others

1.3.1 The transfer function (TF)

\subsubsection{Others}

i. Cross-entropy

ii. Control-constraints
- higher accuracy

and performance

- feasible for speed

independent classifiers

- can combine both time

and frequency domains

- able to classify terrain conditions

determination of the

process noise variance

before estimation

- speed independent

classifier with less training effort

- able to detect potholes

required fewer parameters

than the model-based approach

- easy, convenient and fast

- frequency domain only further complex modelling and understanding vehicle dynamics control mechanism

\footnotetext{
- not directly yield the expression of the excitation - limited to a constant speed (can be eliminated when combined TF with small time span)
}

too much computing time unsprung mass accelerations non-linear and complex models remains costly 
Table 7 Advantages and disadvantages of response-based methods (Continued)

\begin{tabular}{|c|c|c|}
\hline Response-based methods & Advantages & Disadvantages \\
\hline iii. Bayesian parameter & low cost regardless of vehicle models & $\begin{array}{l}\text { a priori information of } \\
\text { the road is required }\end{array}$ \\
\hline iv. Microphone & $\begin{array}{l}\text { feasible for the combination } \\
\text { of techniques }\end{array}$ & $\begin{array}{l}\text { the susceptibility to } \\
\text { signal contaminations }\end{array}$ \\
\hline v. Modulating function & $\begin{array}{l}\text { fulfil the real-time and noise } \\
\text { suppression requirements }\end{array}$ & $\begin{array}{l}\text { particularly for } \\
\text { off-road vehicles }\end{array}$ \\
\hline \multicolumn{3}{|l|}{$\begin{array}{l}\text { 2. Road roughness estimation } \\
\text { and pothole detection }\end{array}$} \\
\hline \multicolumn{3}{|l|}{ 2.1 Threshold-based methods } \\
\hline 2.1.1 Thresholds only & $\begin{array}{l}\text { simplest methods (for PD } \\
\text { purpose) with fix thresholds }\end{array}$ & $\begin{array}{l}\text { threshold value varies } \\
\text { with different types } \\
\text { of smartphones, roads, } \\
\text { vehicles, the condition } \\
\text { of vehicles. }\end{array}$ \\
\hline 2.1.2 Combined thresholds and others & $\begin{array}{l}\text { overcome drawbacks of the } \\
\text { threshold-based methods }\end{array}$ & \\
\hline i. with signal processing approaches & $\begin{array}{l}\text { - able to detect the severity } \\
\text { of potholes, differentiate } \\
\text { potholes and humps }\end{array}$ & \\
\hline ii. with MLs to train detectors & $\begin{array}{l}\text { - clustering of different road } \\
\text { anomalies with simple algorithms }\end{array}$ & $\begin{array}{l}\text { training datasets required } \\
\text { which are not able to collect } \\
\text { in some cases }\end{array}$ \\
\hline 2.2 Signal processing & $\begin{array}{l}\text { - able include both PD and RE } \\
\text { in the same system } \\
\text { - deal with GPS errors, data } \\
\text { aggregation, device installation } \\
\text { and orientation, crowdsourcing } \\
\text { - higher performance and accuracy } \\
\text { - suitable for data aggregation } \\
\text { regardless of different configuration } \\
\text { (e.g. velocity, orientation, suspension) }\end{array}$ & complicated analysis \\
\hline 2.2.1 PSD and RMS acceleration & calculate IRI value & not able to detect a pothole \\
\hline 2.2.2 RIF transformation & $\begin{array}{l}\text { - feasible for connected vehicles } \\
\text { - both PD and RE considering } \\
\text { a fleet of vehicles }\end{array}$ & advanced signal processing \\
\hline $\begin{array}{l}\text { 2.2.3 Adaptive threshold } \\
\text { (e.g. DWT) }\end{array}$ & $\begin{array}{l}\text { less training effort as } \\
\text { compared to MLs }\end{array}$ & \\
\hline $\begin{array}{l}2.3 \text { Data-driven } \\
\text { approach (MLs) }\end{array}$ & $\begin{array}{l}\text { - various techniques to be } \\
\text { applied to select the best alternative } \\
\text { - easier to implement in the } \\
\text { smartphone for crowdsourcing }\end{array}$ & $\begin{array}{l}\text { a huge amount of training } \\
\text { datasets required which are } \\
\text { not able to collect in } \\
\text { some cases }\end{array}$ \\
\hline $\begin{array}{l}\text { 2.3.1 Only MLs } \\
\text { (e.g. ANN) }\end{array}$ & $\begin{array}{l}\text { simple using of raw } \\
\text { acceleration data and filter }\end{array}$ & \\
\hline $\begin{array}{l}\text { 2.3.2 Combined MLs } \\
\text { and feature extraction }\end{array}$ & $\begin{array}{l}\text { - able to eliminate speed } \\
\text { dependence, suspension variation } \\
\text { - higher accuracy }\end{array}$ & \\
\hline
\end{tabular}

signal processing and machine-learning methods. Following this, all reviewed documents and discussion are summarised on their advantages and disadvantages (see Table 7) which should be beneficial for further research in this field.

As for future research, it should be of strong value-add to focus on several potential topics as follows. Firstly, the airsuspension system (as an active-suspension type) has not been investigated by any research for $\mathrm{PR}$ whereas most existing studies are about passive suspension system (67\%). The reason is probably due to the high modelling complexity of the air-suspension while it is noted that the Macpherson controllable suspension was simulated and simplified in [2]. Secondly, MLs have demonstrated their capability for multiple functions such as ANN algorithms for PR and PD in [33], PR and RE in $[8,134]$ in which certain limitation in the estimation accuracy, vehicle parameters or speed variance can be further studied to develop comprehensive algorithms. 
Thirdly, although fleet vehicle approach seems to be less complicated to deal with, a comprehensive PBPM for PD and RE for the fleet of public transport (e.g. bus fleet) is still missing, except the general concept in [64] or smart PD in [124]. This fleet vehicle approach faces fewer challenges on data aggregation since vehicle fleets are quite identical, with lower GPS errors caused by lane-by-lane difference and without crowdsourcing platform. Such a system, once developed, will be beneficial in maintaining the road condition for public transport such as the citywide bus lane system in Singapore, London or worldwide BRT lane system, in which the road surfaces often deteriorate quickly due to heavyloading from heavy-duty vehicles [136]. Fourthly, how to localise precise road roughness condition and potholes by lane accuracy (probably less than $0.5 \mathrm{~m}$ accuracy) is crucial to make the PBPM comparable to conventional Pavement management system, in which APP instruments currently measure road surface lane-by-lane. Higher GPS localisation of potholes also serves to optimise the trajectories of following vehicles in the connected platooning to avoid road defects by passing the vibration information from the leader to the followers. This can be done with the help of the future development of sensor technology. Lastly, the intensive on-going research on RIF and TWIT [95-101] as the alternatives for IRI in connected vehicle environment will be promising for large-scale implementation.

\footnotetext{
Abbreviations

acc, def, dis: Acceleration, deflection, displacement; ANFIS: Adaptive neurofuzzy inference system; APP: Automated pavement profiler; C, F, S: Connected vehicle, Fleet vehicle, Smartphone approach; DNN: Deep neural networks; DOF: Degree-of-freedom; DTW: Dynamic time warping; DWT: Discrete wavelet transforms; FFT: Fast Fourier transform; GPS, Data, Crowd: GPS accuracy, data fusion/aggregation, crowdsourcing platform; GZERO: The sensor senses a 0-g vibration; IRI: International roughness index; KF: Kalman filter; LPA: Longitudinal profile analyser; MLs: Machine-learning techniques; NARX: Bayesian-regularised nonlinear autoregressive exogenous model; NN/ANN: Neural network/artificial neural network; P, SA, A, tyre: Passive, semi-active, active suspension system, tyre dynamics; PBPM: Vehicle probe-based pavement management; PCA: Principal component analysis; PD: Pothole detection; PNN: Probabilistic neural network; PR: Road profile reconstruction/estimation or road roughness classification; PSD: Power spectral density; Q, H, F, 1/5: Quarter, half, full vehicle model, 1/5 vehicle model; RE: Roughness index estimation; RF: Random forest classifier; RIF: Road impact factor; SM: Sliding mode observer; STDEV(Z): The standard deviation of Z-acc above threshold in a window; SVM: Support vector machine; Ter: Terrain classification; TF: Transfer function; TWIT: Time-wavelength-intensity-transform; VDC: Vehicle dynamics control; Z-acc/ Z-thresh: Vertical acceleration/vertical threshold; Z-DIFF: The difference of consecutive Z-acc above threshold
}

\section{Acknowledgements}

This work is part of the PhD study of the first author and is financially supported by the National Research Foundation Singapore under its Campus for Research Excellence and Technological Enterprise (CREATE) programme. This work was supported by the German Research Foundation (DFG) and the Technical University of Munich (TUM) in the framework of the Open Access Publishing Program.

\section{Authors' contributions}

TN was the main initiator and author. His major contribution to the paper is as follows: study conceptualisation and design, data collection, analysis and interpretation of results, draft preparation. BL and YDW have also drafted the manuscript and made editings. All authors reviewed the results and approved the final version of the manuscript.

\section{Funding}

National Research Foundation Singapore (NRF).

Availability of data and materials

Available articles from journal and conference.

\section{Competing interests}

The authors declare that they have no competing interests.

\section{Author details}

${ }^{1}$ Institute of Road, Railway and Airfield Construction, Technische Universität München, Baumbachstraße 7, 81245 Munich, Germany. ${ }^{2}$ TUMCREATE Ltd, 1 Create Way, \#10-02 CREATE Tower, Singapore 138602, Singapore. ${ }^{3}$ Centre for Infrastructure System, Nanyang Technological University, N1-01b-51, 50 Nanyang Avenue, Singapore 639798, Singapore. ${ }^{4}$ Faculty of Road and Bridge Engineering, University of Science and Technology - The University of Danang, 54 Nguyen Luong Bang Street, Danang City, Lien Chieu District, Vietnam.

Received: 17 April 2019 Accepted: 6 September 2019

Published online: 15 October 2019

\section{References}

1. Daily Mail Online (2010) Potholes causing more than $£ 1 \mathrm{~m}$ damage to cars every day. https://www.dailymail.co.uk/news/article-1168103/Potholescausing-1m-damage-cars-EVERY-day.html. Accessed 26 Mar 2019.

2. Qin, Y., Wei, C., Tang, X., Zhang, N., Dong, M., \& Hu, C. (2018). A novel nonlinear road profile classification approach for controllable suspension system: Simulation and experimental validation. Mechanical Systems and Signal Processing. https://doi.org/10.1016/j.ymssp.2018.07.015.

3. ASTM E1364-95. (2017). Standard test method for measuring road roughness by static level method. West Conshohocken: American Society for Testing and Materials.

4. Doumiati, M., Victorino, A., Charara, A., \& Lechner, D. (2011). Estimation of road profile for vehicle dynamics motion: Experimental validation (pp. 52375242). San Francisco: Proceedings of the American control conference.

5. Imine, H., Delanne, Y., \& M'Sirdi, N. K. (2006). Road profile input estimation in vehicle dynamics simulation. Vehicle System Dynamics, 44, 285-303. https:// doi.org/10.1080/00423110500333840.

6. McCann, R., \& Nguyen, S. (2007). System identification for a model-based observer of a road roughness profiler. In 2007 IEEE region 5 technical conference, TPS (pp. 336-343).

7. Kumar, R., Mukherjee, A., \& Singh, V. P. (2017). Community sensor network for monitoring road roughness using smartphones. Journal of Computing in Civil Engineering, 31, 1-11. https://doi.org/10.1061/(ASCE)CP.1943-5487.0000624.

8. Zhang, Z., Sun, C., Bridgelall, R., \& Sun, M. (2018). Road profile reconstruction using connected vehicle responses and wavelet analysis. Journal of Terramechanics, 80, 21-30. https://doi.org/10.1016/j.terra.2018.10.004.

9. Sauerwein, P. M., \& Smith, B. L. (2011). Investigation of the implementation of a probe-vehicle based pavement roughness estimation system. Charlottesville: Center for Transportation Studies.

10. Chugh, G., Bansal, D., \& Sofat, S. (2014). Road condition detection using smartphone sensors: A survey. International Journal of Electronic and Electrical Engineering, 7, 595-602.

11. Wahlstrom, J., Skog, I., \& Handel, P. (2017). Smartphone-based vehicle telematics: A ten-year anniversary. IEEE Transactions on Intelligent Transportation Systems, 18, 2802-2825. https://doi.org/10.1109/TTS.2017.2680468.

12. Van Wee, B., \& Banister, D. (2016). How to write a literature review paper? Transport Reviews, 36, 278-288. https://doi.org/10.1080/01441647.2015.1065456.

13. Burnham, J. F. (2006). Scopus database: A review. Biomedical Digital Libraries, 3, 1-8. https://doi.org/10.1186/1742-5581-3-1.

14. Jacsó, P. (2005). Google scholar: The pros and the cons. Online Information Review, 29, 208-214. https://doi.org/10.1108/14684520510598066. 
15. Tseng, H. E., \& Hrovat, D. (2015). State of the art survey: Active and semiactive suspension control. Vehicle System Dynamics, 53, 1034-1062. https:// doi.org/10.1080/00423114.2015.1037313.

16. Doumiati, M., Victorino, A., Charara, A., \& Lechner, D. (2011). Estimation of road profile for vehicle dynamics motion: Experimental validation. In Proceedings of the 2011 American control conference (pp. 5237-5242). https:// doi.org/10.1109/ACC.2011.5991595.

17. Yu, W., Zhang, X., Guo, K., Karimi, H. R., Ma, F., \& Zheng, F. (2013). Adaptive real-time estimation on road disturbances properties considering load variation via vehicle vertical dynamics. Mathematical Problems in Engineering, 2013, 1-9. https://doi.org/10.1155/2013/283528.

18. Fauriat, W., Mattrand, C., Gayton, N., Beakou, A., \& Cembrzynski, T. (2016). Estimation of road profile variability from measured vehicle responses. Vehicle System Dynamics, 3114. https://doi.org/10.1080/00423114.2016.1145243.

19. Gim, J., \& Ahn, C. (2018). Imu-based virtual road profile sensor for vehicle localization. Sensors (Switzerland), 18. https://doi.org/10.3390/s18103344.

20. Haddar, M., Baslamisli, S. C., Chaari, R., Chaari, F., \& Haddar, M. (2019). Road profile identification with an algebraic estimator. Proceedings of the Institution of Mechanical Engineers, Part C: Journal of Mechanical Engineering Science, 233, 1139-1155. https://doi.org/10.1177/0954406218767470.

21. Wang, Z., Dong, M., Qin, Y., Du, Y., Zhao, F., \& Gu, L. (2017). Suspension system state estimation using adaptive Kalman filtering based on road classification. Vehicle System Dynamics, 55, 371-398. https://doi.org/10.1080/00423114.2016.1267374.

22. Qin, Y., Langari, R., Wang, Z., Xiang, C., \& Dong, M. (2017). Road profile estimation for semi-active suspension using an adaptive Kalman filter and an adaptive super-twisting observer. In Proceedings of the American control conference (pp. 973-978). https://doi.org/10. 23919/ACC.2017.7963079.

23. Rabhi, A., M'sirdi, N. K., Fridman, L., \& Delanne, Y. (2006). Second order sliding mode observer for estimation of road profile. In Proceedings of the 2006 international workshop on variable structure systems (pp. 161-165). Alghero: VSS'06.

24. Rath, J. J., Veluvolu, K. C., \& Defoort, M. (2014). Estimation of road profile for suspension systems using adaptive super-twisting observer. In 2014 European control conference, ECC (pp. 1675-1680). https:/doi.org/10.1109/ECC.2014.6862248.

25. Rath, J. J., Member, S., Veluvolu, K. C., Member, S., \& Defoort, M. (2015). Simultaneous estimation of road profile and tire road friction for automotive vehicle. IEEE Transactions on Vehicular Technology, 64, 44614471. https://doi.org/10.1109/TVT.2014.2373434.

26. Arat, M. A., Taheri, S., \& Holweg, E. (2015). Road profile estimation for active suspension applications. SAE International Journal of Passenger Cars Mechanical Systems, 8. https://doi.org/10.4271/2015-01-0651.

27. Doumiati, M., Erhart, S., Martinez, J., Sename, O., \& Dugard, L. (2014). Adaptive control scheme for road profile estimation: Application to vehicle dynamics. In Proceedings of the 19th world congress the International Federation of Automatic Control (pp. 8445-8450). Cape Town: IFAC.

28. Tudón-martínez, J. C., Fergani, S., Sename, O., Martinez, J. J., Moralesmenendez, R., \& Dugard, L. (2015). Adaptive road profile estimation in semiactive car suspensions. IEEE Transactions on Control Systems Technology, 23, 2293-2305. https://doi.org/10.1109/TCST.2015.2413937.

29. Doumiati, M., Jairo, J., Molina, M., et al. (2017). Road profile estimation using an adaptive Youla- kučera parametric observer: Comparison to real profilers. Control Engineering Practice, Elsevier, 61, 270-278.

30. Rahman, M., \& Rideout, G. (2012). Using the lead vehicle as preview sensor in convoy vehicle active suspension control. Vehicle System Dynamics, 50, 1923-1948. https://doi.org/10.1080/00423114.2012.707801.

31. Tudon-Martinez, J. C., Fergani, S., Sename, O., Morales-Menendez, R., \& Dugard, L. (2014). Online road profile estimation in automotive vehicles (pp. 2370-2375). Strasbourg: European control conference (ECC).

32. Li, Z., Kalabic, U. V., Kolmanovsky, I. V., Atkins, E. M., Lu, J., \& Filev, D. P. (2016). Simultaneous road profile estimation and anomaly detection with an input observer and a jump diffusion process estimator. In Proceedings of the American Control Conference, 2016-July (pp. 16931698). https://doi.org/10.1109/ACC.2016.7525160

33. Ngwangwa, H. M., Heyns, P. S., Labuschagne, F. J. J., \& Kululanga, G. K. (2010). Reconstruction of road defects and road roughness classification using vehicle responses with artificial neural networks simulation. Journal of Terramechanics, 47, 97-111. https://doi.org/10.1016/j.jterra.2009.08.007.

34. Ngwangwa, H. M., \& Heyns, P. S. (2014). Application of an ANN-based methodology for road surface condition identification on mining vehicles and roads. Journal of Terramechanics, 53, 59-74. https://doi.org/ 10.1016/j.jterra.2014.03.006.
35. Ngwangwa, H. M., Heyns, P. S., Breytenbach, H. G. A., \& Els, P. S. (2014). Reconstruction of road defects and road roughness classification using artificial neural networks simulation and vehicle dynamic responses: Application to experimental data. Journal of Terramechanics, 53, 1-18. https://doi.org/10.1016/j.jterra.2014.03.002.

36. Yousefzadeh, M., Azadi, S., \& Soltani, A. (2010). Road profile estimation using neural network algorithm. Journal of Mechanical Science and Technology, 24, 743-754. https://doi.org/10.1007/s12206-010-0113-1.

37. Li, Z., Yu, W., \& Cui, X. (2018). Online classification of road roughness conditions with vehicle unsprung mass acceleration by sliding time window. Shock and Vibration, 2018. https://doi.org/10.1155/2018/5131434

38. Wang, S., Kodagoda, S., Wang, Z., \& Dissanayake, G. (2011). Multiple sensor based terrain classification. Melbourne: Proceedings of the 2011 Australasian conference on robotics and automation.

39. Wang, S., Kodagoda, S., Shi, L., \& Wang, H. (2017). Road-terrain classification for land vehicles: Employing an acceleration-based approach. IEEE Vehicular Technology Magazine, 12, 34-41. https://doi.org/10.1109/MVT.2017.2656949.

40. Wang, S., Khushaba, R., \& Kodagoda, S. (2012). Towards speed-independent road-type classification (pp. 614-619). Guangzhou: 2012 12th International Conference on Control, Automation, Robotics and Vision, ICARCV 2012.

41. Ward, C. C., \& lagnemma, K. (2009). Speed-independent vibration-based terrain classification for passenger vehicles. Vehicle System Dynamics, 47, 1095-1113. https://doi.org/10.1080/00423110802450193.

42. Qin, Y., Langari, R., Wang, Z., Xiang, C., \& Dong, M. (2017). Road excitation classification for semi-active suspension system with deep neural networks. Journal of Intelligent Fuzzy Systems, 33, 1907-1918. https:/doi.org/10.3233/JIFS-161860.

43. Qin, Y., Xiang, C., Wang, Z., \& Dong, M. (2018). Road excitation classification for semi-active suspension system based on system response. JVC/Journal of Vibration and Control, 24, 2732-2748. https:// doi.org/10.1177/1077546317693432

44. Qin, Y., Dong, M., Zhao, F., Langari, R., \& Gu, L. (2015). Road profile classification for vehicle semi-active suspension system based on adaptive neuro-fuzzy inference system. In Proceedings of the IEEE conference on decision and control (pp. 1533-1538). Osaka: Institute of Electrical and Electronics Engineers Inc.

45. Qin, Y., Langari, R., \& Gu, L. (2014). The use of vehicle dynamic response to estimate road profile input in time domain. In ASME 2014 dynamic systems and control conference, DSCC 2014. San Antonio: American Society of Mechanical Engineers.

46. Qin, Y., Dong, M., Langari, R., Gu, L., \& Guan, J. (2015). Adaptive hybrid control of vehicle semiactive suspension based on road profile estimation. Shock and Vibration, 2015, 14-17. https://doi.org/10.1155/2015/636739.

47. Qin, Y., Wang, Z., Xiang, C., Hashemi, E., Khajepour, A., \& Huang, Y. (2019). Speed independent road classification strategy based on vehicle response: Theory and experimental validation. Mechanical Systems and Signal Processing, 117, 653-666. https://doi.org/10.1016/j.ymssp.2018.07.035.

48. Ben Hassen, D., Miladi, M., Abbes, M. S., Baslamisli, S. C., Chaari, F., \& Haddar, M. (2019). Road profile estimation using the dynamic responses of the full vehicle model. Applied Acoustics, 147, 87-99. https://doi.org/10.1016/j. apacoust.2017.12.007.

49. Gorges, C., Öztürk, K., \& Liebich, R. (2019). Impact detection using a machine learning approach and experimental road roughness classification. Mechanical Systems and Signal Processing, 117, 738-756. https://doi.org/10. 1016/j.ymssp.2018.07.043.

50. González, A., O'Brien, E. J., Li, Y. Y., \& Cashell, K. (2008). The use of vehicle acceleration measurements to estimate road roughness. Vehicle System Dynamics, 46, 483-499. https://doi.org/10.1080/00423110701485050.

51. ISO8608:2016(en). (2016). Mechanical vibration - road surface profiles reporting of measured data. In International Organization for Standardization.

52. Qin, Y., Guan, J., \& Gu, L. (2012). The research of road profile estimation based on acceleration measurement. Applied Mechanics and Materials, 226-228, 1614-1617. https://doi.org/10.4028/www.scientific.net/AMM.226-228.1614.

53. Gorges, C., Öztürk, K., \& Liebich, R. (2018). Road classification for twowheeled vehicles. Vehicle System Dynamics, 56, 1289-1314. https://doi.org/ 10.1080/00423114.2017.1413197.

54. Wang, Q., McDaniel, J. G., Sun, N. X., \& Wang, M. L. (2013). Road profile estimation of city roads using DTPS. San Diego: Proceedings of SPIE - The International Society for Optical Engineering.

55. Harris, N. K., Gonzalez, A., OBrien, E. J., \& McGetrick, P. (2010). Characterisation of pavement profile heights using accelerometer readings and a combinatorial optimisation technique. Journal of Sound and Vibration 329, 497-508. https://doi.org/10.1016/j.jsv.2009.09.035. 
56. Burger, M. (2014). Calculating road input data for vehicle simulation. Multibody System Dynamics, 31, 93-110. https://doi.org/10.1007/s1 1044-013-9380-9.

57. Noack, M., Botha, T., Hamersma, H. A., Ivanov, V., Reger, J., \& Els, S. (2018). Road profile estimation with modulation function based sensor fusion and series expansion for input reconstruction. In Proceedings - 2018 IEEE 15th international workshop on advanced motion control, AMC 2018 (pp. 547-552). Tokyo: Institute of Electrical and Electronics Engineers Inc.

58. Heyns, T., Heyns, P. S., \& De Villiers, J. P. (2012). A method for real-time condition monitoring of haul roads based on bayesian parameter estimation. Journal of Terramechanics, 49, 103-113. https://doi.org/10.1016/j. jterra.2011.12.001.

59. Johnsson, R., \& Odelius, J. (2012). Methods for road texture estimation using vehicle measurements. In Proceedings of the international conference on noise and vibration engineering (ISMA 2012) (pp. 1573-1582).

60. Li, X., \& Goldberg, D. W. (2018). Toward a mobile crowdsensing system for road surface assessment. Computers, Environment and Urban Systems, 69, 51-62. https://doi.org/10.1016/j.compenvurbsys.2017.12.005.

61. Harris, D. K., Alipour, M., Acton, S. T., Messeri, L. R., Vaccari, A., \& Barnes, L. E. (2017). The citizen engineer: Urban infrastructure monitoring via crowd-sourced data analytics. In S. J.G. (Ed.), Structures congress 2017: Business, professional practice, education, research, and disaster management - selected papers from the structures congress 2017 (pp. 495-510). Denver: American Society of Civil Engineers (ASCE).

62. Mednis, A., Strazdins, G., Zviedris, R., Kanonirs, G., \& Selavo, L. (2011). Real time pothole detection using android smartphones with accelerometers. In 2011 International conference on distributed computing in sensor systems and workshops. Barcelona: DCOSS'11.

63. Badurowicz, M., Cieplak, T., \& Montusiewicz, J. (2016). The cloud computing stream analysis system for road artefacts detection Communications in Computer and Information Science, 608, 360-369. https://doi.org/10.1007/978-3-319-39207-3_31.

64. De Zoysa, K. (2007). A public transport system based sensor network for road surface condition monitoring. In Workshop on Networked System for Developing Regions. NSDR'O7. New York, Kyoto: Association for Computer Machinery.

65. Yagi, K. (2010). Extensional smartphone probe for road bump detection (pp. 110). Busan: 17 th ITS world congress.

66. Nomura, T., \& Shiraishi, Y. (2015). A method for estimating road surface conditions with a smartphone. International Journal of Informatics Society, 7, 29-36.

67. Limkar, S., Rajmane, O., Bhosale, A., \& Rane, V. (2018). Small effort to build Pune as a smart city: Smart real-time road condition detection and efficient management system. Smart Innovation, Systems and Technologies, 78, 609621. https://doi.org/10.1007/978-981-10-5547-8_63.

68. Rishiwal, V., \& Khan, H. (2016). Automatic pothole and speed breaker detection using android system. In 39th international convention on information and communication technology, electronics and microelectronics, MIPRO 2016 - proceedings (pp. 1270-1273). Opatija: Institute of Electrical and Electronics Engineers Inc.

69. Mukherjee, A., \& Majhi, S. (2016). Characterisation of road bumps using smartphones. European Transport Research Review. https://doi.org/10. 1007/s12544-016-0200-1

70. Mehta, J., Mathur, V., Agarwal, D., Sharma, A., \& Prakasha, K. (2017). Pothole detection and analysis system (PODAS) for real time data using sensor networks. Journal of Engineering and Applied Sciences, 12, 3090-3097. https:// doi.org/10.3923/jeasci.2017.3090.3097.

71. Syed, B., Pal, A., Srinivasarengan, K., \& Balamuralidhar, P. (2012). A smart transport application of cyber-physical systems: Road surface monitoring with mobile devices. In Proceedings of the international conference on sensing technology, ICST (pp. 8-12). https://doi.org/10. 1109/ICSensT.2012.6461796.

72. Harikrishnan, P. M., \& Varun, P. G. (2017). Vehicle vibration signal processing for road surface monitoring. IEEE Sensors Journal, 17, 5192-5197.

73. Wang, H.-W., Chen, C.-H., Cheng, D.-Y., Lin, C.-H., \& Lo, C.-C. (2015). A real-time pothole detection approach for intelligent transportation system. Mathematical Problems in Engineering, 2015. https://doi.org/10. 1155/2015/869627.

74. Aljaafreh, A., Alawasa, K., Alja'afreh, S., \& Abadleh, A. (2017). Fuzzy inference system for speed bumps detection using smart phone accelerometer sensor. Journal of Telecommunication, Electronic and Computer Engineering, 9, 133-136.

75. Aleadelat, W., Wright, C. H. G., \& Ksaibati, K. (2018). Estimation of gravel roads ride quality through an android-based smartphone. Transportation Research Record. https://doi.org/10.1177/0361198118758693.
76. Grabowski, D., Szczodrak, M., \& Czyzewski, A. (2018). Economical methods for measuring road surface roughness. Metrology and Measurement Systems, 25, 533-549. https://doi.org/10.24425/123905.

77. Ali, J., \& Dyo, V. (2017). Coverage and mobile sensor placement for vehicles on predetermined routes: A greedy heuristic approach. In ICETE 2017 proceedings of the 14th international joint conference on e-business and telecommunications (pp. 83-88)

78. Astarita, V., Caruso, M. V., Danieli, G., Festa, D. C., Giofrè, V. P., luele, T., \& Vaiana, R. (2012). A mobile application for road surface quality control: UNlquALroad. Procedia - Social and Behavioral Sciences. https://doi.org/10. 1016/j.sbspro.2012.09.828.

79. Vittorio, A., Rosolino, V., Teresa, I., Vittoria, C. M., \& Vincenzo, P. G. (2014). Automated sensing system for monitoring of road surface quality by mobile devices. Procedia-Social and Behavioral Sciences. (pp. 111, 242-251).

80. Singh, G., Bansal, D., Sofat, S., \& Aggarwal, N. (2017). Smart patrolling: An efficient road surface monitoring using smartphone sensors and crowdsourcing. Pervasive and Mobile Computing, 40, 71-88. https://doi.org/ 10.1016/.jpmcj.2017.06.002.

81. Yi, C.-W., Chuang, Y.-T., \& Nian, C.-S. (2015). Toward crowdsourcing-based road pavement monitoring by mobile sensing technologies. IEEE Transactions on Intelligent Transportation Systems, 16, 1905-1917. https://doi. org/10.1109/TITS.2014.2378511.

82. Chen, K., Lu, M., Fan, X., Wei, M., \& Wu, J. (2011). Road condition monitoring using on-board three-axis accelerometer and GPS sensor. In International ICST conference on communications and networking. China (pp. 1032-1037).

83. Du, Y., Liu, C., Wu, D., \& Jiang, S. (2014). Measurement of international roughness index by using Z-axis accelerometers and GPS. In Mathematical Problems in Engineering, 2014. https://doi.org/10.1155/2014/928980.

84. Dawkins, J., Bevly, D., Powell, B., \& Bishop, R. (2011). Investigation of pavement maintenance applications of Intellidrive. University of Virginia Technical Report: Center for Transportation Studies, University of Virginia.

85. Zeng, H., Park, H., Smith, B. L., \& Parkany, E. (2018). Feasibility assessment of a smartphone-based application to estimate road roughness. KSCE Journal of Civil Engineering, 22, 3120-3129. https://doi.org/10.1007/s12205-017-1008-9.

86. Abulizi, N., Kawamura, A., Tomiyama, K., \& Shun, F. (2016). Measuring and evaluating of road roughness conditions with a compact road profiler and ArcGIS. Journal of Traffic and Transportation Engineering (English Edition), 3, 398-411. https://doi.org/10.1016/j.jtte.2016.09.004.

87. Douangphachanh, V., \& Oneyama, H. (2014). A study on the use of smartphones under realistic settings to estimate road roughness condition. EURASIP Journal on Wireless Communications and Networking, 2014, 1-11.

88. Douangphachanh, V., \& Oneyama, H. (2013). A study on the use of smartphones for road roughness condition estimation. Journal of the Eastern Asia Society for Transportation Studies, 10, 1551-1564.

89. Li, J., Zhang, Z., \& Wang, W. (2019). New approach for estimating international roughness index based on the inverse pseudo excitation method. Journal of Transportation Engineering Part B: Pavements, 145. https://doi.org/10.1061/JPEODX.0000093.

90. Ndoye, M., Vanjari, S. V., Huh, H., Krogmeier, J. V., Bullock, D. M., Hedges, C. A. , \& Adewunmi, A. (2006). Sensing and signal processing for a distributed pavement monitoring system. In 2006 IEEE 12th digital signal processing workshop and 4th IEEE signal processing education workshop (pp. 162-167). https://doi.org/10.1109/DSPWS.2006.265446.

91. Alessandroni, G., Klopfenstein, L. C., Delpriori, S., et al. (2014). SmartRoadSense: Collaborative road surface condition monitoring. In UBICOMM 2014: The Eighth International Conference on Mobile Ubiquitous Computing, systems, services and technologies SmartRoadSense (pp. 210-215).

92. Alessandroni, G., Carini, A., Lattanzi, E., Freschi, V., \& Bogliolo, A. (2017). A study on the influence of speed on road roughness sensing: The SmartRoadSense case. Sensors (Switzerland), 17. https://doi.org/10.3390/ s17020305.

93. Ndoye, M., Barker, A. M., Krogmeier, J. V., \& Bullock, D. M. (2011). A recursive multiscale correlation-averaging algorithm for an automated distributed roadcondition-monitoring system. IEEE Transactions on Intelligent Transportation Systems, 12, 795-808. https:/doi.org/10.1109/TITS.2011.2132799.

94. Bridgelall, R. (2014). Connected vehicle approach for pavement roughness evaluation. Journal of Infrastructure Systems, 20, 04013001 . https://doi.org/10. 1061/(ASCE)IS.1943-555X.0000167.

95. Bridgelall, R. (2015). Inertial sensor sample rate selection for ride quality measures. Journal of Infrastructure Systems, 21, 04014039. https://doi.org/10. 1061/(ASCE)IS.1943-555X.0000225. 
96. Bridgelall, R., Huang, Y., Zhang, Z., \& Deng, F. (2016). Precision enhancement of pavement roughness localization with connected vehicles. Measurement Science and Technology, 27. https://doi.org/10.1088/0957-0233/27/2/025012.

97. Bridgelall, R., \& Tolliver, D. (2018). Accuracy enhancement of roadway anomaly localization using connected vehicles. International Journal of Pavement Engineering, 19, 75-81. https://doi.org/10.1080/10298436.2016. 1162306.

98. Bridgelall, R., Rahman, M. T., Tolliver, D. D., \& Daleiden, J. F. (2016). Use of connected vehicles to characterize ride quality. Transportation Research Record: Journal of the Transportation Research Board, 2589, 119-126. https:// doi.org/10.3141/2589-13.

99. Bridgelall, R. (2014). Precision bounds of pavement deterioration forecasts from connected vehicles. Journal of Infrastructure Systems, 21, 04014033. https://doi.org/10.1061/(asce)is.1943-555x.0000218.

100. Bridgelall, R., Hough, J., \& Tolliver, D. (2017). Characterising pavement roughness at non-uniform speeds using connected vehicles. International Journal of Pavement Engineering, 8436, 1-7. https://doi.org/10.1080/ 10298436.2017.1366768.

101. Bridgelall, R., Rahman, M. T., Tolliver, D., \& Daleiden, J. F. (2017). Wavelength sensitivity of roughness measurements using connected vehicles. International Journal of Pavement Engineering, 8436, 1-7. https://doi.org/10. 1080/10298436.2017.1316645.

102. Eriksson, J., Girod, L., Hull, B., Newton, R., Madden, S., \& Balakrishnan, H. (2008). The pothole patrol: Using a mobile sensor network for road surface monitoring (pp. 29-39). Breckenridge: MobiSys'08 - proceedings of the 6th international conference on Mobile systems, applications, and services.

103. Mohan, P., Venkata, N. P., \& Ramachandran, R. (2008). Nericell: Using mobile smartphones for rich monitoring of road and traffic conditions. In Proceedings of the 6 th international conference on embedded networked sensor systems (pp. 323-336). Raleigh: SenSys 2008.

104. Mohan, P., Venkata, N. P., \& Ramachandran, R. (2008). TrafficSense: Rich monitoring of road and traffic conditions using mobile smartphones. Tech. Rep. no. MSR-TR-2008-59.

105. Gunawan, F. E., Yanfi, \& Soewito, B. (2015). A vibratory-based method for road damage classification. In 2015 international seminar on intelligent technology and its applications, ISITIA 2015 - proceeding (pp. 1-4). Surabaya: Institute of Electrical and Electronics Engineers Inc.

106. Das, T., Prashanth, M., Venkata, N. P., Ramachandran, R., \& Asankhaya, S. (2010). PRISM : Platform for remote sensing using smartphones. San Francisco: Proceedings of the 8th international conference on Mobile systems, applications, and services - MobiSys '10.

107. Monteserin, A. (2018). Potholes vs. speed bumps: A multivariate time series classification approach. In I. Lykourentzou, M. G. Armentano, \& HFTA (Eds.), CEUR workshop proceedings (pp. 36-40). CEUR-WS.

108. Xue, G., Zhu, H., Hu, Z., Yu, J., Zhu, Y., \& Luo, Y. (2017). Pothole in the dark: Perceiving pothole profiles with participatory urban vehicles. IEEE Transactions on Mobile Computing, 16, 1408-1419. https://doi.org/10.1109/TMC.2016.2597839.

109. Chen, K., Lu, M., Tan, G., \& Wu, J. (2014). CRSM: Crowdsourcing based road surface monitoring. In Proceedings - 2013 IEEE international conference on high performance computing and communications, HPCC 2013 and 2013 IEEE international conference on embedded and ubiquitous computing, EUC 2013 (pp. 2151-2158). Zhangjiajie, Hunan: IEEE Computer Society.

110. Chen, K., Tan, G., Lu, M., \& Wu, J. (2016). CRSM: A practical crowdsourcing-based road surface monitoring system. Wireless Networks, 22, 765-779. https://doi.org/10.1007/s11276-015-0996-y.

111. Ren, J., \& Liu, D. (2017). PADS: A reliable pothole detection system using machine learning. In Lecture Notes in Computer Science (including subseries Lecture Notes in Artificial Intelligence and Lecture Notes in Bioinformatics), 10135 LNCS (pp. 327-338). https://doi.org/10.1007/978-3319-52015-5_33.

112. Ghadge, M., Pandey, D., \& Kalbande, D. (2016). Machine learning approach for predicting bumps on road. In M. Aradhya \& S. K. N (Eds.), Proceedings of the 2015 international conference on applied and theoretical computing and communication technology, iCATccT 2015 (pp. 481-485). Davangere: Institute of Electrical and Electronics Engineers Inc.

113. Hoffmann, M., Mock, M., \& May, M. (2013). Road-quality classification and bump detection with bicycle-mouted smartphones. In CEUR workshop proceedings (pp. 39-43).

114. Tai, Y., Chan, C., \& Hsu, J. Y. (2010). Automatic road anomaly detection using smart mobile device. In 2010 15th conference on artificial intelligence and applications (TAAl) (pp. 1-8).
115. Bose, B., Dutta, J., Ghosh, S., Pramanick, P., \& Roy, S. (2018). D\&Sense: Detection of driving patterns and road anomalies. In Proceedings - 2018 3rd International Conference On Internet of Things: Smart Innovation and Usages, IOT-SIU 2018 (pp. 1-7). https://doi.org/10.1109/loT-SIU.2018.8519861.

116. Mohamed, A., Fouad, M. M. M., \& Elhariri, E. (2014). RoadMonitor: An intelligent road surface condition monitoring system. Warsaw: 7th IEEE International Conference Intelligent Systems IS'2014.

117. Seraj, F., van der Zwaag, B. J., Dilo, A., Luarasi, T., \& Havinga, P. J. M. (2014). RoADS: A road pavement monitoring system for anomaly detection using smart phones. In 1st international workshop on machine learning for urban sensor data, SenseML 2014 (pp. 1-16). Berlin: Springer.

118. Seraj, F., Meratnia, N., Zhang, K., Havinga, P. J. M., \& Turkes, O. (2015). A smartphone based method to enhance road pavement anomaly detection by analyzing the driver behavior (pp. 1169-1177). Osaka: In proceedings of the UbiComp '15.

119. Perttunen, M., Mazhelis, O., Cong, F., et al. (2011). Distributed road surface condition monitoring using mobile phones (pp. 64-78). Banff: International conference on ubiquitous intelligence and computing.

120. Cong, F., Hautakangas, H., Nieminen, J., Mazhelis, O., Perttunen, M., Riekki, J., \& Ristaniemi, T. (2013). Applying wavelet packet decomposition and oneclass support vector machine on vehicle acceleration traces for road anomaly detection. Lecture Notes in Computer Science, 7951 LNCS, 291-299. https://doi.org/10.1007/978-3-642-39065-4-36.

121. Bhoraskar, R., Vankadhara, N., Raman, B., \& Kulkarni, P. (2012). Wolverine: Traffic and road condition estimation using smartphone sensors. In 2012 fourth international conference on communication systems and networks (COMSNETS 2012). Bangalore: IEEE.

122. Fox, A., Kumar, B. V. K. V., Chen, J., \& Bai, F. (2015). Crowdsourcing undersampled vehicular sensor data for pothole detection. In 2015 12th annual IEEE international conference on sensing, communication, and networking, SECON 2015 (pp. 515-523). Seattle: Institute of Electrical and Electronics Engineers Inc.

123. Fox, A., Kumar, B. V. K. V., Chen, J., \& Bai, F. (2017). Multi-lane pothole detection from crowdsourced undersampled vehicle sensor data. IEEE Transactions on Mobile Computing, 16, 3417-3430. https://doi.org/10.1109/ TMC.2017.2690995.

124. Anaissi, A., Khoa, N. L. D., Rakotoarivelo, T., Alamdari, M. M., \& Wang, Y. (2019). Smart pothole detection system using vehicle-mounted sensors and machine learning. Journal of Civil Structural Health Monitoring, 9, 91-102. https://doi.org/10.1007/s13349-019-00323-0.

125. Silva, N., Soares, J., Shah, V., Santos, M. Y., \& Rodrigues, H. (2017). Anomaly detection in roads with a data mining approach. Procedia Computer Science, 121, 415-422. https://doi.org/10.1016/j.procs.2017.11.056.

126. Silva, N., Shah, V., Soares, J., \& Rodrigues, H. (2018). Road anomalies detection system evaluation. Sensors (Switzerland), 18. https://doi.org/10.3390/s18071984.

127. Jang, J., Smyth, A. W., Yang, Y., \& Cavalcanti, D. (2015). Road surface condition monitoring via multiple sensor-equipped vehicles. In Proceedings - IEEE INFOCOM (pp. 43-44). Hong Kong: Institute of Electrical and Electronics Engineers Inc.

128. Jang, J., Yang, Y., Smyth, A. W., Cavalcanti, D., \& Kumar, R. (2017). Framework of data acquisition and integration for the detection of pavement distress via multiple vehicles. Journal of Computing in Civil Engineering, 31, 1-15. https://doi.org/10.1061/(ASCE)CP.

129. Allouch, A., Koubaa, A., Abbes, T., \& Ammar, A. (2017). RoadSense: Smartphone application to estimate road conditions using accelerometer and gyroscope. IEEE Sensors Journal, 17, 4231-4238. https://doi.org/10.1109/JSEN.2017.2702739.

130. Carlos, M. R., Aragon, M. E., Gonzalez, L. C., Escalante, H. J., \& Martinez, F. (2018). Evaluation of detection approaches for road anomalies based on accelerometer readings-addressing who's who. IEEE Transactions on Intelligent Transportation Systems, 19, 3334-3343. https://doi.org/10.1109/TITS.2017.2773084.

131. Lin, J.-L., Peng, Z.-Q., \& Lai, R. K. (2017). Improving pavement anomaly detection using backward feature elimination. Lecture Notes in Business Information Processing, 288, 341-349. https://doi.org/10. 1007/978-3-319-59336-4_24.

132. Celaya-Padilla, J. M., Galván-Tejada, C. E., López-Monteagudo, F. E., et al. (2018). Speed bump detection using accelerometric features: A genetic algorithm approach. Sensors (Switzerland), 18. https://doi.org/10.3390/s18020443.

133. Laubis, K., Simko, V., \& Schuller, A. (2016). Road condition measurement and assessment: A crowd based sensing approach (pp. 1-10). Dublin: Thirty Seventh International Conference on Information Systems.

134. Zhang, Z., Sun, C., Bridgelall, R., \& Sun, M. (2018). Application of a machine learning method to evaluate road roughness from connected vehicles. 
Journal of Transportation Engineering Part B: Pavements, 144, 1-13. https:// doi.org/10.1061/JPEODX.0000074.

135. Aksamit, P., \& Szmechta, M. (2011). Distributed, mobile, social system for road surface defects detection (pp. 37-40). Floriana: ISCIII 2011 - 5th international symposium on computational intelligence and intelligent informatics.

136. Nguyen, T., Lechner, B., Wong, Y. D., \& Tan, J. Y. (2019). Bus ride index - a refined approach to evaluate road surface irregularities. Road Mater Pavement Des. https://doi.org/10.1080/14680629.2019.1625806.

\section{Publisher's Note}

Springer Nature remains neutral with regard to jurisdictional claims in published maps and institutional affiliations.

\section{Submit your manuscript to a SpringerOpen ${ }^{\circ}$ journal and benefit from:}

- Convenient online submission

- Rigorous peer review

- Open access: articles freely available online

- High visibility within the field

- Retaining the copyright to your article

Submit your next manuscript at $\boldsymbol{\nabla}$ springeropen.com 